\title{
State-Related Inhibition by GABA and Glycine of Transmission in Clarke's Column
}

\author{
Niwat Taepavarapruk, Shelly A. McErlane, and Peter J. Soja \\ Faculty of Pharmaceutical Sciences, Division of Pharmacology and Toxicology, The University of British Columbia, \\ Vancouver, British Columbia, Canada V6T 1 Z3
}

\begin{abstract}
During the state of active sleep (AS), Clarke's column dorsal spinocerebellar tract (DSCT) neurons undergo a marked reduction in their spontaneous and excitatory amino acid (EAA)evoked responses. The present study was performed to examine the magnitude, consistency of AS-specific suppression, and potential role of classical inhibitory amino acids GABA and glycine (GLY) in mediating this phenomenon.

AS-specific suppression of DSCT neurons, expressed as the reduction in mean spontaneous firing rate during $A S$ versus the preceding episode of wakefulness, was compared across three consecutive sleep cycles (SC), each consisting of wakefulness (W), AS, and awakening from AS (RW). Spontaneous spike rate did not differ during $\mathrm{W}$ or RW between SC1, SC2, and SC3. AS-specific suppression of spontaneous firing rate was found to be consistent and measured $40.3,31.5$, and $41.6 \%$ in SC1, SC2, and SC3, respectively, indicating that such inhibition is marked and stable for pharmacological analyses.
\end{abstract}

Based on rudimentary evoked potential studies performed in the late 1960s, it has been casually accepted that ascending sensory neurotransmission from the lumbar spinal cord is attenuated during desynchronized (active) sleep (AS) (Carli et al., 1967). Indeed, recent experimental human studies indicate that somatosensory processing is diminished during sleep, particularly AS (Nielsen et al., 1993; Symons, 1993; Lavigne et al., 2000). Presumably, this fundamental state-dependent phenomenon occurs on a daily basis throughout an individual's normal healthy life span, and yet its neurobiological basis and aberrant manifestations remain poorly understood.

Few investigations have used chronic recording techniques to monitor the activity of individual lumbar sensory neurons in an effort to unravel which sensory pathways and brain mechanisms are involved. In this regard, the activity of Clarke's column dorsal spinocerebellar tract (DSCT) neurons, which constitute a major spinal cord sensory pathway conveying an array of proprioceptive as well as exteroceptive afferent signals to the cerebellum (Walmsley, 1991; Bosco and Poppele, 2001) and thalamus (Johansson and Silfvenius, 1977), have been recently monitored during the sleep-wake cycle.

\footnotetext{
Received Nov. 12, 2001; revised April 1, 2002; accepted April 23, 2002.

This work was supported in part by National Institutes of Health, National Institute of Neurological Disorders and Stroke Grants NS 34716 and NS 32306 and National Institute of General Medical Sciences Grant GM 25877 (P.J.S.). N.T. was supported by a Royal Thai Government Graduate Fellowship.

Correspondence should be addressed to Dr. P. J. Soja, Faculty of Pharmaceutical Sciences, The University of British Columbia, 2146 East Mall, Vancouver, British Columbia, V6T $1 Z 3$ Canada. E-mail: Soja@Exchange.Ubc.Ca.

Copyright (C) 2002 Society for Neuroscience $0270-6474 / 02 / 225777-12 \$ 15.00 / 0$
}

Microiontophoretic experiments were performed in which the magnitude of AS-specific suppression of spontaneous spike activity was measured over three consecutive SCs: SC1control (no drug), SC2-test (drug), and SC3-recovery (no drug). The magnitude of AS-specific suppression during SC2-test measured only 11.7 or $14.6 \%$ in the presence of $\mathrm{GABA}_{A}$ antagonist bicuculline (BIC) or GLY antagonist strychnine (STY), respectively. Coadministration of BIC and STY abolished ASspecific suppression. AS-specific suppression of EAA-evoked DSCT spike activity was also abolished in SC2-test after BIC or STY, respectively.

We conclude that GABA and GLY mediate behavioral statespecific inhibition of ascending sensory transmission via Clarke's column DSCT neurons.

Key words: bicuculline; GABA; glutamate; glycine; sleep; spinocerebellar; strychnine

During AS, spontaneous and excitatory amino acid (EAA)induced transmission through the DSCT is markedly attenuated when compared with wakefulness or quiet sleep (Soja et al., 1995, 1996, 2001b). Both dynamic presynaptic and postsynaptic inhibitory processes were suggested to underlie AS-specific suppression. Alternatively, withdrawal of supraspinal facilitatory influences and/or a passive disfacilitation of excitatory muscular afferent input that is secondary to postsynaptic inhibition of motoneurons, during natural AS (Chase et al., 1989; Soja et al., 1991) also could account for the suppression of DSCT neuron activity. Experiments designed to assess whether putative inhibitory neurotransmitters likely to cause dynamic presynaptic and postsynaptic inhibition in the spinal cord are released in the vicinity of DSCT neurons during natural AS are required to support the dynamic inhibition hypothesis and are prerequisite to elucidating the neural pathways underlying the behavioral statespecific reduction of sensory throughput to higher brain centers.

Glycine (GLY) and GABA are classical inhibitory neurotransmitters in the mammalian spinal cord. In particular, DSCT neurons possess defined substrates for presynaptic and postsynaptic inhibition mediated by GABA and/or GLY (Jankowska and Padel, 1984; Curtis et al., 1986; Walmsley et al., 1987; Maxwell and Riddell, 1999; Watson and Bazzaz, 2001). Accordingly, we compared the magnitude of AS-specific suppression of spontaneous and EAA-induced spike activity of individual DSCT neurons in the absence, presence, and recovery from the juxtacellular microiontophoretic administration of the $\mathrm{GABA}_{\mathrm{A}}$ receptor antagonist bicuculline (BIC) or the GLY receptor antagonist strychnine (STY). 
These inhibitory amino acid antagonists blocked suppression of DSCT neuron activity. indicating that, during AS, GABA and GLY are released in the vicinity of DSCT neurons. Dynamic presynaptic and postsynaptic inhibitory processes involving classical inhibitory neurotransmitters underlie the behavioral statespecific inhibition of Clarke's column DSCT lumbar sensory tract neurons.

\section{MATERIALS AND METHODS}

\section{Surgical procedures}

All experimental procedures reported herein were performed on a total of three adult cats and complied with national and international (Canadian Council on Animal Care, 1993; National Research Council, 1996) and institutional (University of British Columbia Animal Care Committee) guidelines. Experiments were performed on intact, unanesthetized cats. Under deep gaseous anesthesia (45-60\% $\mathrm{N}_{2} 0$ in $1.5-2.5 \%$ halothane-oxygen mixture), the animals were implanted with head and lumbar restraining devices. Electrodes were implanted into the frontal sinus [electroencephalogram (EEG)], lateral geniculate nucleus of the thalamus [pontogeniculo-occipital (PGO) wave activity], the orbital plate [electro-oculogram (EOG)], and neck muscles [electromyogram (EMG)]. Through the use of these electrodes, each animal's behavioral states of wakefulness and sleep could be determined.

A complete recovery over a 3 month period was required before any recordings from DSCT neurons were performed. This prolonged recovery period minimized any alterations in sleep cycles and/or change in neuronal excitability that might occur with shorter recovery periods (Soja et al., 1995, 1999, 2001b). Procedures for surgical implantation, the gradual adaptation to painless head and lumbar restraint during the latter half of the 3 month recovery period, identification of sleep-wake states, and antidromic identification of spinal projection neurons in the chronic intact cat have been previously described in detail (Soja et al., $1995,2001 a, b)$. Each preparation readily cycled between sleep and wakefulness during each experimental recording session, which typically lasted between 5 and $6 \mathrm{hr}$. Recording sessions were performed over 4 consecutive days/week (Soja et al., 1996). DSCT neuron activity was recorded over multiple sleep cycles (SC). Each SC consisted of the following states: wakefulness, AS, and awakening from AS (RW). Electrophysiological criteria for determining states of W, AS, and RW were identical to those reported in detail previously (Soja et al., 1995, 1996, 2001b).

\section{Antidromic identification procedures}

Low-intensity search stimuli (0.05 msec, $0.5 \mathrm{~Hz}, 100-300 \mu \mathrm{A})$ were applied to a "floating" stimulating electrode that was stereotaxically positioned within the anterior cerebellar lobule (Fig. 1A) to "backfire" DSCT neurons using conventional criteria (i.e., constant latency, collision between spontaneous and antidromically propagated spikes, and high-frequency following) (Soja et al., 1995, 1996). All DSCT neurons reported herein satisfied these criteria for antidromicity (Fig. 1B). Antidromic search stimuli or drug microiontophoresis did not cause any indications of arousal, EEG desynchronization, or interfere with the animal's normal cycling between sleep and wakefulness.

\section{Microiontophoresis procedures}

Seven-barrel coaxial glass micropipettes were positioned in Clarke's column at the $\mathrm{L}_{3}$ spinal cord segment for extracellular unit recording and simultaneous juxtacellular drug microiontophoresis (Fig. 1A, magnified box enclosure). The central carbon fiber-containing recording barrel was surrounded by six barrels filled with glutamate (GLU) (0.5 M), pH 8.0, or AMPA (0.01 M), pH 8.0, inhibitory amino acid agonists GABA and GLY (both $0.5 \mathrm{M}$ ), $\mathrm{pH} 3.5$, inhibitory amino acid antagonists bicuculline methiodide (BIC) (0.02 M), pH 4.0, strychnine sulfate (STY) (0.1 M), pH 5.0 , or sodium chloride $(\mathrm{NaCl})(4 \mathrm{M})$. All drugs used for microiontophoresis were dissolved in distilled water and were obtained from Sigma (St. Louis, MO). Negative currents (in nanoamperes) were applied to the GLU and AMPA drug barrels to eject excitatory agents. GABA, GLY, BIC, and STY were ejected using positive currents (see Results). Retention currents $(10 \mathrm{nA})$ of opposite polarity used for ejection were continuously applied to each drug barrel to minimize spontaneous leakage. Automatic current neutralization procedures were performed using a drug barrel containing $4 \mathrm{M} \mathrm{NaCl}$ during drug microiontophoresis (Soja et al., 1996).

\section{Data collection and analyses}

Spontaneous spike activity. Spontaneous spike activity during wakefulness and sleep states were analyzed using Spike 2 software, version 3.2 (Cambridge Electronic Design, Cambridge, UK) and methods previously described (Soja et al., 2001b). Briefly, the average spontaneous firing frequency (in spikes per second) was calculated for each neuron using 1 min epochs of spike activity during each behavioral state within each SC. Data obtained from the state of W was compared with data obtained during the middle portion of AS and subsequent episode of RW. In accordance with previous work from our laboratory, only those DSCT neurons that underwent $>15 \%$ decrease in firing rate during AS when compared with $\mathrm{W}$ were tested further using either protocol 1 or 2 below, (Soja et al., 1996). The average spike rate for individual neurons was calculated during W, AS, and RW in each SC. The magnitude of AS-specific suppression of spontaneous spike activity from DSCT neurons was determined by the following formula: $100-[($ mean firing rate $\{$ spikes/sec $\}$ during AS/mean firing rate during $\mathrm{W}) \times 100)]$. The absolute and relative group mean $( \pm$ SEM) changes in spontaneous spike activities were tabulated (Tables 1,2).

Excitatory amino acid-evoked spike activity. GLU- and AMPA-evoked responses were quantified according to procedures outlined by Soja et al (2001b). Briefly, for each DSCT neuron, consecutive responses to GLU (10-15 sec ejection epoch, $20 \mathrm{sec}$ intervals) or AMPA (6 sec ejection epoch, $60 \mathrm{sec}$ intervals) were plotted as perievent histograms (bin width, $1 \mathrm{sec}$ ) around drug ejections using a computer subroutine written for Spike 2 software. GLU- or AMPA-evoked perievent histograms were compiled as the computer average of 4 (AMPA) or 5 (GLU) responses from each corresponding episode of W, AS, and RW. For each averaged GLU response, spike rate values (in spikes per second) were determined during the $10 \mathrm{sec}$ period immediately preceding the onset of GLU ejection and the last $10 \mathrm{sec}$ around the peak during GLU ejection. The magnitude of GLU-evoked responses was then determined by subtracting average spontaneous spike activity values from average values during GLU. AMPA-evoked responses were prolonged and relatively weak when compared with GLU responses (see Results). Accordingly, the magnitude of AMPA-evoked responses was determined in a similar manner to GLU responses, except that the average spontaneous spike activity values were subtracted from corresponding average values $10 \mathrm{sec}$ after the cessation of AMPA ejection currents. Finally, for each cell, the magnitude of AS-specific suppression of EAA-evoked responses was determined by the following formula: $100-$ [(GLU response during AS/GLU response during $\mathrm{W})] \times 100$. The absolute and relative group mean ( \pm SEM) values in spontaneous and EAA-evoked spike activities were tabulated (Table 3 ).

\section{Experimental paradigms}

Two experimental paradigms were used in this study. In each paradigm, multibarrel recording micropipettes were lowered in vertical tracts directed at Clarke's column $0.25-0.5 \mathrm{~mm}$ lateral to the midline of the spinal cord.

Paradigm 1. In the first paradigm, each identified DSCT neuron was recorded with a coaxial multibarrel pipette and served as its own control over multiple SCs (Fig. $2 A$ ). The rationale here was to examine the consistency of AS-specific suppression of DSCT neuronal spontaneous firing rate from one SC to the next. Consistent firing rates across each respective behavioral state in each sleep cycle would indicate stable reproducible inhibition and adequate drug retention in adjacent drug barrels.

Paradigm 2. A second paradigm (Fig. 2B) was used to assess the pharmacological basis for AS-specific suppression of DSCT neuronal activity. Here, the magnitude of AS-specific suppression of spontaneous spike activity of DSCT neurons was determined in SC1-control. AS-specific inhibition in SC1-control was then measured and compared with that obtained in SC2-test in the presence of the antagonist ejected microionotphoretically. Previous studies have found that the firing rate and pattern of DSCT neurons does not differ between wakefulness and quiet sleep or subsequent awakening from AS (Soja et al., 1995, 1996). Accordingly, in the present study, drug microiontophoresis was always performed in SC2-test during either wakefulness or quiet sleep before AS.

Inhibitory amino acid antagonists BIC and/or STY were ejected continuously in a sustained manner using ejection currents that provided a complete blockade of the appropriate GABA- or GLY-induced inhibition of spontaneous spike activity. Once this was confirmed, ejection of the antagonist was maintained continuously throughout the AS period for SC2-test. This approach provided concentrations of BIC or STY 


\section{A. Experimental Scheme}

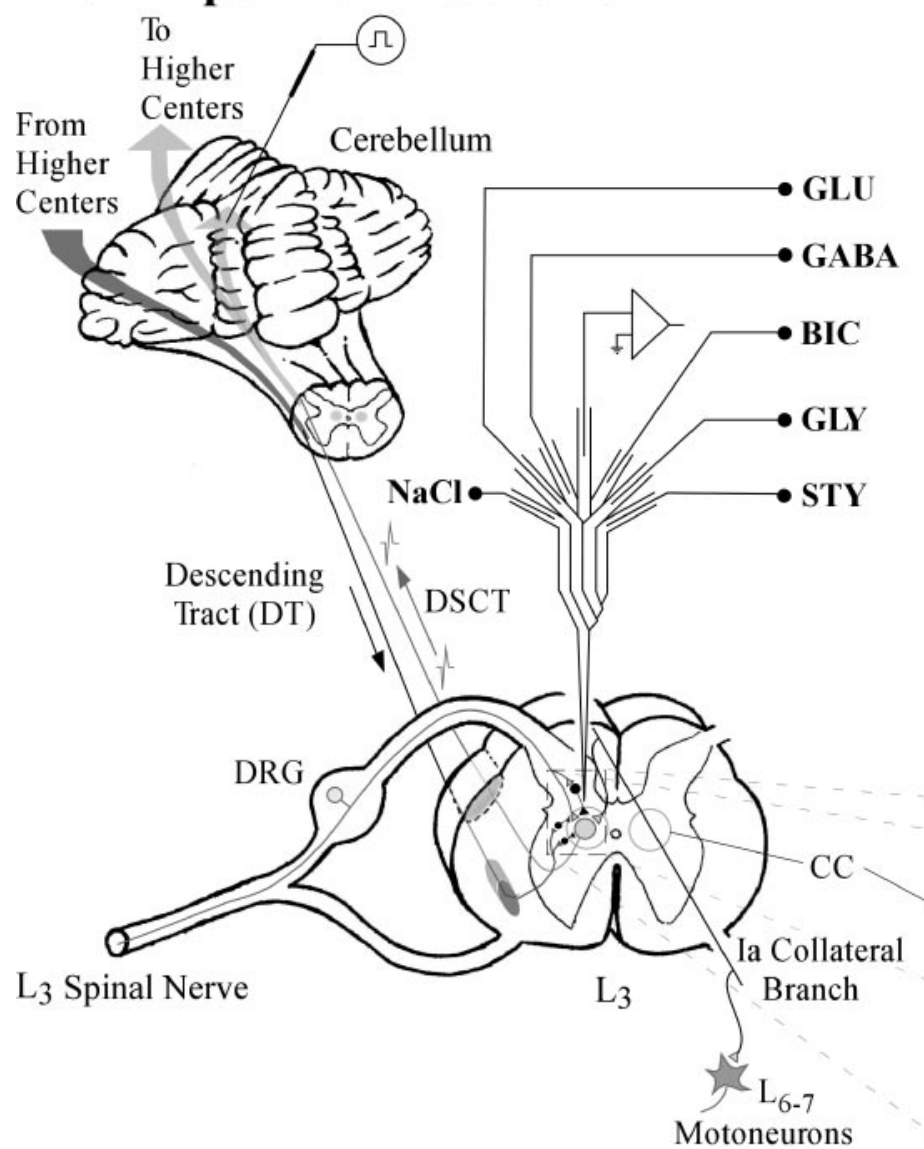

\section{B. DSCT Neuron Identification}

1. Constant Latency

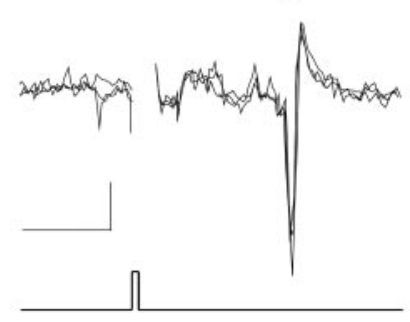

2. $500 \mathrm{~Hz}$ Following
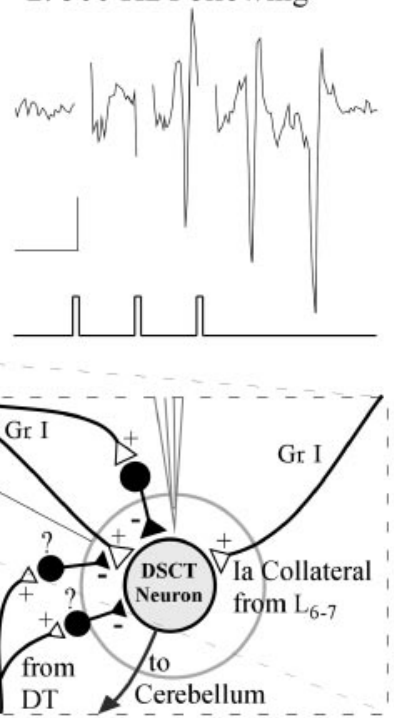

3. Spontaneous Collision
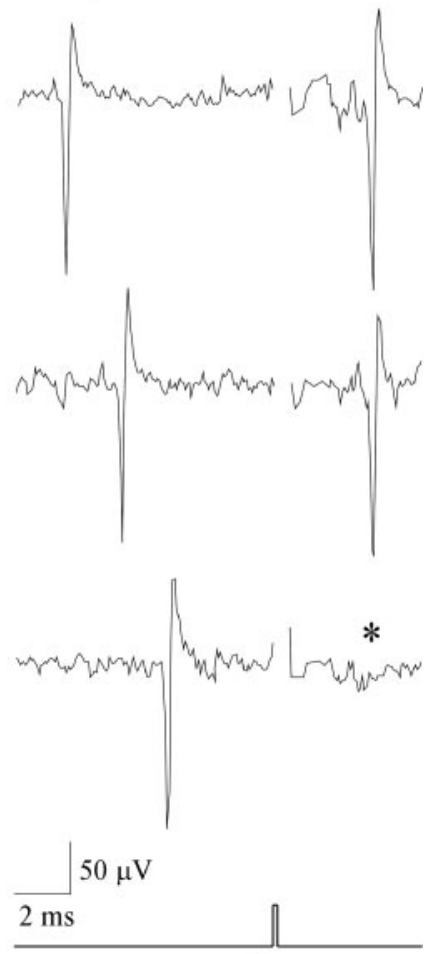

Stim.

Figure 1. The procedure. A, Spike activity from Clarke's column $(C C)$ DSCT neurons in the $\mathrm{L}_{3}$ spinal cord segment was recorded using a seven-barrel glass micropipette that allowed microiontophoretic juxtacellular ejections of excitatory and inhibitory amino acid agonists and antagonists. The boxed enclosure illustrates a magnified portion of the spinal gray matter highlighting known synaptic linkages from primary afferent neurons (DRG) to DSCT neurons. DSCT neurons also receive inputs from local inhibitory interneurons (Hongo et al., 1983; Rudomin et al., 1990). The question mark indicates that such interneurons may mediate AS-specific suppression of DSCT neurons. Finally, DSCT neurons also receive excitatory input from Ia afferent terminals via collateral branches of parent axons projecting to L6-L7 motoneuron pools. $B$, Antidromic criteria used to confirm that recorded neurons in the $\mathrm{L}_{3}$ segment projected to the cerebellum: (1) constant, invariant latency after threshold stimuli applied to the stimulating electrode in the cerebellum, (2) the ability to follow high-frequency $(500 \mathrm{~Hz})$ trains of stimuli denoted by the trigger record under the bottom panel, and (3) collision $(*)$ of spontaneously occurring action potentials, from afferent inputs, with those propagated antidromically from the cerebellum. Calibration: $50 \mu \mathrm{V}$, 2 msec.

sufficient to affect synaptic inhibition at distal sites of the large multipolar DSCT neurons (Walmsley, 1991) of Clarke's column in a manner applied for motoneurons (Chase et al., 1989; Soja et al., 1991).

After completion of SC2-test, the antagonist ejection was terminated and the cells' firing rate monitored again throughout SC3-recovery to ensure that AS-related suppression had returned following drug microiontophoresis (Fig. 2B). A maximum of two DSCT neurons were re- corded in this manner over multiple SCs on any given day of the 4 consecutive day recording period.

\section{Statistical analyses}

Significant differences in the spontaneous and GLU- or AMPA-evoked spike rate of DSCT neurons during W, AS, and RW across multiple SCs were determined by the use of a repeated measures ANOVA test and

Table 1. Consistency of AS-specific suppression of DSCT neurons across three consecutive SCs

\begin{tabular}{|c|c|c|c|c|c|c|c|c|c|}
\hline & \multicolumn{3}{|l|}{$\mathrm{SC} 1$} & \multicolumn{3}{|l|}{$\mathrm{SC} 2$} & \multicolumn{3}{|l|}{$\mathrm{SC} 3$} \\
\hline & W & AS & RW & W & AS & RW & W & AS & RW \\
\hline Spikes/sec & $20.9 \pm 1.9$ & $12.5 \pm 1.6^{* * *}$ & $19.3 \pm 2.4$ & $20.6 \pm 2.6$ & $14.1 \pm 2.4^{* * *}$ & $21.4 \pm 2.5$ & $19.2 \pm 1.7$ & $11.2 \pm 2.0^{* * * *}$ & $18.9 \pm 2.1$ \\
\hline $\begin{array}{l}\% \text { change } \\
\% \text { of control }\end{array}$ & $(100 \%)$ & $\begin{array}{l}\downarrow 40.3 \pm 5.5 \\
(59.7 \%)\end{array}$ & $\begin{array}{l}\downarrow 7.6 \pm 8.7 \\
(92.4 \%)\end{array}$ & $(100 \%)$ & $\begin{array}{l}\downarrow 31.5 \pm 4.8 \\
(68.5 \%)\end{array}$ & $\begin{array}{l}\uparrow 4.0 \pm 4.9 \\
(104 \%)\end{array}$ & $(100 \%)$ & $\begin{array}{l}\downarrow 41.6 \pm 6.6 \\
(58.4 \%)\end{array}$ & $\begin{array}{l}\downarrow 1.3 \pm 4.1 \\
(98.7 \%)\end{array}$ \\
\hline
\end{tabular}

DSCT neurons were recorded during W, AS, and RW in three separate SCs according to Paradigm 1 (Fig. 2; see Materials and Methods). The group mean firing rate ( \pm SEM) in spikes per second of 10 DSCT neurons is presented. The relative change in firing rate during AS or the subsequent episode of RW, compared with preceding episode of W is also presented for each SC. Downward arrows reflect percentage of decrease. Under control conditions, consistent AS-specific suppression occurred from one SC to the next (see AS: SC1-3 vs Wakefulness: SC1 $-3,{ }^{* * *} p<0.005$, ANOVA). 
Table 2. Effect of BIC and STY on AS-specific suppression of DSCT neurons

\begin{tabular}{|c|c|c|c|c|c|c|c|c|c|}
\hline & \multicolumn{3}{|c|}{ SC1-control } & \multicolumn{3}{|l|}{ SC2-test } & \multicolumn{3}{|c|}{ SC3-recovery } \\
\hline & $\mathrm{W}$ & AS & RW & $\mathrm{W}$ & AS & RW & $\mathrm{W}$ & AS & RW \\
\hline \multicolumn{10}{|l|}{$\mathrm{BIC}(n=12)$} \\
\hline Spikes/sec & $23.4 \pm 3.6$ & $14.5 \pm 2.3^{* * *}$ & $23.2 \pm 3.0$ & $31.7 \pm 4.2 * * * *$ & $28.0 \pm 4.1^{*}$ & $36.3 \pm 4.0$ & $27.5 \pm 2.5$ & $18.4 \pm 1.7^{* *}$ & $27.8 \pm 3.3$ \\
\hline$\%$ change & & $\downarrow 38.1 \pm 5.0$ & $\downarrow 0.8 \pm 6.5$ & & $\downarrow 11.7 \pm 3.9$ & $\uparrow 14.4 \pm 5.2$ & & $\downarrow 33.0 \pm 5.0$ & $\uparrow 1.1 \pm 4.9$ \\
\hline$\%$ of control & $(100 \%)$ & $(61.9 \%)$ & $(99.2 \%)$ & $(100 \%)$ & $(88.3 \%)$ & $(114.4 \%)$ & $(100 \%)$ & $(67.0 \%)$ & $(101.1 \%)$ \\
\hline \multicolumn{10}{|l|}{$\operatorname{STY}(n=9)$} \\
\hline Spikes/sec & $25.5 \pm 3.0$ & $16.0 \pm 1.5^{* *}$ & $24.7 \pm 2.6$ & $28.1 \pm 2.9^{* * * *}$ & $24.0 \pm 3.2^{*}$ & $29.2 \pm 3.7$ & $26.2 \pm 3.4$ & $19.4 \pm 2.0^{*}$ & $29.3 \pm 4.3$ \\
\hline $\begin{array}{l}\% \text { change } \\
\% \text { of control }\end{array}$ & $(100 \%)$ & $\begin{array}{l}\downarrow 37.2 \pm 5.8 \\
(62.8 \%)\end{array}$ & $\begin{array}{l}\downarrow 3.0 \pm 2.9 \\
(97 \%)\end{array}$ & $(100 \%)$ & $\begin{array}{l}\downarrow 14.6 \pm 7.1 \\
(85.4 \%)\end{array}$ & $\begin{array}{l}\uparrow 4.2 \pm 5.1 \\
(104.2 \%)\end{array}$ & $(100 \%)$ & $\begin{array}{l}\downarrow 26.1 \pm 5.3 \\
(73.9 \%)\end{array}$ & $\begin{array}{l}\uparrow 11.6 \pm 5.2 \\
(111.6 \%)\end{array}$ \\
\hline \multicolumn{10}{|c|}{$\mathrm{BIC}+\operatorname{STY}(n=6)$} \\
\hline Spikes/sec & $20.4 \pm 5.3$ & $12.3 \pm 3.1^{*}$ & $18.7 \pm 4.2$ & $25.6 \pm 5.6^{* * * *}$ & $28.6 \pm 6.3$ & $27.2 \pm 5.9$ & $21.1 \pm 3.0$ & $17.2 \pm 2.9$ & $19.8 \pm 4.3$ \\
\hline $\begin{array}{l}\% \text { change } \\
\% \text { of control }\end{array}$ & $(100 \%)$ & $\begin{array}{l}\downarrow 39.7 \pm 17.2 \\
(60.3 \%)\end{array}$ & $\begin{array}{l}\downarrow 8.3 \pm 8.3 \\
(91.7 \%)\end{array}$ & $(100 \%)$ & $\begin{array}{l}\uparrow 11.7 \pm 4.8 \\
(111.7 \%)\end{array}$ & $\begin{array}{l}\uparrow 6.1 \pm 2.0 \\
(106.1 \%)\end{array}$ & $(100 \%)$ & $\begin{array}{l}\downarrow 18.4 \pm 1.7 \\
(81.6 \%)\end{array}$ & $\begin{array}{l}\downarrow 6.4 \pm 16.2 \\
(93.6 \%)\end{array}$ \\
\hline
\end{tabular}

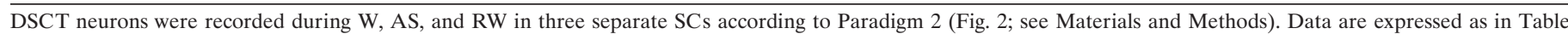

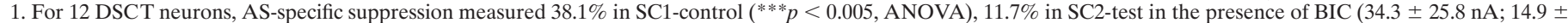

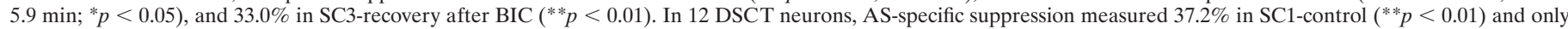

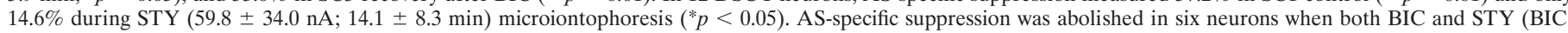

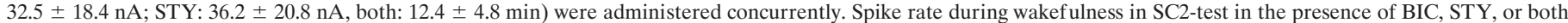
agents together was enhanced relative to the corresponding spike rate value during W in SC1 (****p $p<0.05$, paired Student's $t$ test).

Table 3. Effect of BIC and STY on AS-specific suppression of spontaneous and EAA-evoked spike activity of DSCT neurons

\begin{tabular}{|c|c|c|c|c|c|c|}
\hline & \multicolumn{3}{|c|}{ Spontaneous } & \multicolumn{3}{|c|}{ EAA-evoked } \\
\hline & $\mathrm{W}$ & AS & RW & $\mathrm{W}$ & AS & RW \\
\hline Control & $24.6 \pm 3.0$ & $19.4 \pm 4.2^{*}$ & $24.5 \pm 3.5$ & $9.2 \pm 1.2$ & $3.1 \pm 2.0^{*}$ & $8.9 \pm 1.2$ \\
\hline$\%$ change & & $\downarrow 21.3 \pm 10.2 \%$ & $\downarrow 0.7 \pm 6.5 \%$ & & $\downarrow 66.4 \pm 26.6 \%$ & $\downarrow 3.8 \pm 10.6 \%$ \\
\hline$\%$ of control & $(100 \%)$ & $(78.7 \%)$ & $(99.3 \%)$ & $(100 \%)$ & $(33.6 \%)$ & $(99.7 \%)$ \\
\hline $\mathrm{BIC}$ & $28.9 \pm 3.7$ & $29.5 \pm 4.4$ & $33.2 \pm 4.1$ & $12.4 \pm 1.9$ & $13.3 \pm 2.1$ & $15.1 \pm 2.9$ \\
\hline$\%$ change & & $\uparrow 2.4 \pm 7.9 \%$ & $\uparrow 15.1 \pm 6.6 \%$ & & $\uparrow 7.4 \pm 7.4 \%$ & $\uparrow 22.4 \pm 16.7 \%$ \\
\hline$\%$ of control & $(100 \%)$ & $(102.4 \%)$ & $(115.1 \%)$ & $(100 \%)$ & $(107.4 \%)$ & $(122.4 \%)$ \\
\hline STY & $28.9 \pm 2.6$ & $25.5 \pm 2.2$ & $30.7 \pm 3.1$ & $12.4 \pm 1.9$ & $13.7 \pm 2.6$ & $12.3 \pm 1.5$ \\
\hline$\%$ change & & $\downarrow 11.8 \pm 3.9 \%$ & $\uparrow 6.2 \pm 4.4 \%$ & & $\uparrow 10.7 \pm 13.1 \%$ & $\downarrow 0.7 \pm 6.6 \%$ \\
\hline$\%$ of control & $(100 \%)$ & $(88.2 \%)$ & $(106.2 \%)$ & $(100 \%)$ & $(110.7 \%)$ & $(99.3 \%)$ \\
\hline
\end{tabular}

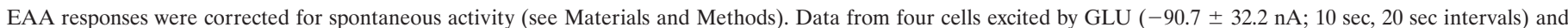

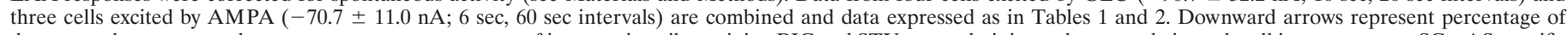

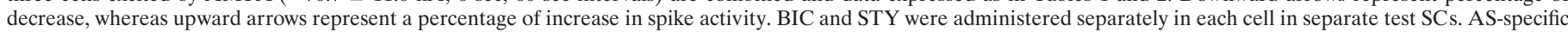

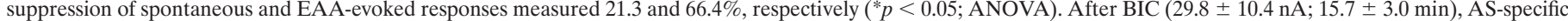

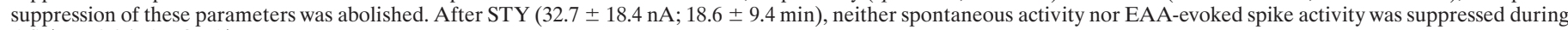
$\operatorname{AS}(p>0.05 ;$ ANOVA).

post hoc Dunnett's method test. In all cases, $p<0.05$ was considered statistically significant. A paired Student's $t$ test was used to assess statistical significance between control spontaneous firing rate during $\mathrm{W}$ in control versus drug-treated (BIC, STY) test conditions as well as the duration of AS episodes across animals or across SCs. $p<0.05$ was considered statistically significant.

\section{RESULTS}

\section{General characteristics of DSCT neurons}

Experiments were performed on a total of 44 antidromically identified (Fig. 1B) DSCT neurons obtained from three cats, all of which displayed robust spontaneous spike activity during the state of wakefulness and suppression of spontaneous spike activity during AS. The group mean ( \pm SD) antidromic latency measured $3.2 \pm 0.6 \mathrm{msec}$ (range, $2.5-5.0 \mathrm{msec}$ ). The estimated mean axonal conduction velocity measured $77.3 \pm 11.2 \mathrm{~m} / \mathrm{sec}$. The average recording time for these cells was $3.4 \pm 0.6 \mathrm{hr}$ (range, 2.0-5.3 hr). Overall, we recorded DSCT neuron activity over a combined total of 129 SCs. The mean duration ( \pm SD) of each active sleep episode measured $4.3 \pm 1.8 \mathrm{~min}$ (range, $0.5-9.2 \mathrm{~min}$ ).
These observations are consistent with those of a previous study of DSCT neurons recorded across sleep and wakefulness (Soja et al., 1996).

\section{Reliability of AS-specific suppression}

Control studies using a seven-barrel recording micropipette were initially performed on 10 DSCT neurons from two animals $(n=$ 5 , cat \#1; $n=5$, cat \#2) to verify that the AS-specific suppression of spike rate could be observed repeatedly across multiple SCs in the presence of controlled retention currents applied to adjacent drug barrels. The paradigm involved recording ongoing spike activity from $\mathrm{L}_{3}$ DSCT neurons through a minimum of three consecutive SCs (Fig. 2A, Paradigm 1) and then comparing the magnitude of AS-specific suppression of spike rate between the three SCs. Table 1 summarizes the mean spike rate in absolute and relative terms for the state of W, AS, and RW in each SC. For each of the 10 DSCT neurons, the mean firing rate was consistent during $\mathrm{W}$ in each SC ( $p>0.05$, ANOVA) (Table 1). AS-specific suppression occurred consistently from one SC to the next and 


\section{A. Paradigm 1}

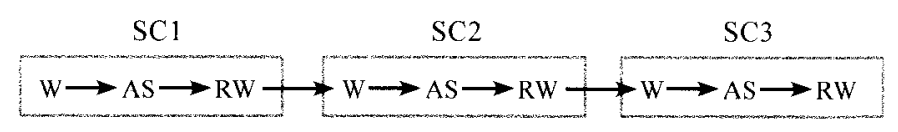

\section{B. Paradigm 2}

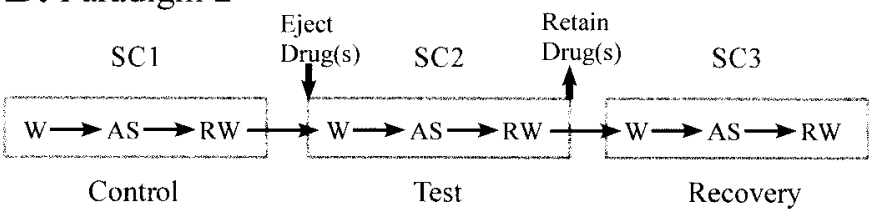

Figure 2. Experimental paradigms designed to assess the consistency $(A)$ and pharmacological sensitivity $(B)$ to GABA antagonist BIC and/or GLY antagonist STY on AS-specific suppression of spontaneous spike activity. Paradigm 1 consisted of three SCs in which the animal shifted from W to AS, and when the animal subsequently awakened from AS (RW). AS-specific suppression of spontaneous spike activity, i.e., percentage of change in spike rate during AS versus W was compared in each SC. The magnitude of AS-specific suppression for 10 DSCT neurons was compared between three consecutive SCs (Table 1). Paradigm 2 was used to assess the magnitude of AS-specific suppression before (SC1-control), during (SC2-test), and after (SC3-recovery) from the microiontophoretic administration of BIC and/or STY (Table 2).

the magnitude of suppression did not differ between each SC (SC1, 40.3\%; SC2, 31.5\%; SC3, 41.6\%; $p>0.05$, ANOVA) (Table $1)$. The mean duration ( \pm SD) of AS in each SC was also the same (SC1: $4.7 \pm 1.7 \mathrm{~min}$; $\mathrm{SC} 2: 4.1 \pm 1.9 \mathrm{~min}$; $\mathrm{SC} 3: 4.6 \pm 1.5 \mathrm{~min}$; $p>0.05$, ANOVA).

Indeed, this pattern of consistent suppression was observed when the spike rate data from cats \#1 and \#2 were compared separately. For example, group mean spike rate $( \pm$ SEM) for five cells in cat \#1 decreased by $41.7 \%$ from $19.1 \pm 2.2$ spikes/sec during W to $11.4 \pm 2.3$ spikes/sec during AS in SC1, by $37.0 \%$ from $17.6 \pm 3.7$ spikes/sec to $11.3 \pm 2.6$ spikes/sec in SC2, and by $39.9 \%$ from $17.1 \pm 2.5 \mathrm{spikes} / \mathrm{sec}$ to $10.1 \pm 2.7 \mathrm{spikes} / \mathrm{sec}$ in SC3, respectively ( $p<0.01$, ANOVA).

In cat \#2, a similar reduction in mean spike rate was observed for 5 other DSCT neurons: a decrease by $40.5 \%$ from $22.7 \pm 3.1$ spikes/sec during W to $13.6 \pm 2.3$ spikes/sec during AS in SC1, by $31.8 \%$ from $23.6 \pm 3.5$ spikes/sec to $17.0 \pm 3.8$ spike/sec in SC2, and by $43.2 \%$ from $20.4 \pm 2.8$ spikes/sec to $12.2 \pm 3.8$ spikes/sec in SC3, respectively ( $p<0.01$, ANOVA). Across each SC, there was no difference in the group mean spike rate during $\mathrm{W}$ and $\mathrm{RW}$ between cat \#1 and 2 nor was there any difference in the magnitude of AS-specific suppression of spontaneous spike activity $(p>0.05$, ANOVA). The mean duration of AS in each SC did not differ ( $p>0.05$, ANOVA) for cat \#1 (SC1: $5.0 \pm 1.1 \mathrm{~min}$, $\mathrm{SC} 2: 5.2 \pm 1.4 \mathrm{~min}, \mathrm{SC} 3: 5.2 \pm 1.6 \mathrm{~min})$ and cat \#2 (SC1: $4.9 \pm$ $1.1 \mathrm{~min}, \mathrm{SC} 2: 5.1 \pm 1.1 \mathrm{~min}, \mathrm{SC} 3: 5.0 \pm 0.8 \mathrm{~min})$.

As presented in Figure $5 A$, a plot of neuronal spike rate during W versus AS for each neuron revealed a distinct pattern of consistent AS-specific suppression across all three SCs and that there is minimal interanimal variability. These data provide a fundamental control for drug microiontophoresis experiments where the pharmacological basis underlying the AS-specific suppression of DSCT neuron activity could be determined reliably.

\section{Pharmacology of AS-specific inhibition}

\section{Spontaneous spike activity}

The GABA antagonist BIC and/or the GLY antagonist STY were assessed for their ability to block the suppression of DSCT neuron activity during AS. This was accomplished in 27 DSCT neurons $(n=10$, cat \#2; $n=17$, cat \#3). The experimental paradigm taken in these particular experiments also required monitoring the activity of each cell over three consecutive SCs (Fig. 2B, Paradigm 2). SC1-control served as a control to establish baseline levels of AS-specific neuronal suppression. The second SC served as a test to assess AS-related suppression of DSCT neuron activity in the presence of sustained release of BIC and/or STY. Finally, the third SC served to determine the recovery of AS-specific suppression after the cessation of release of the inhibitory amino acid antagonists (Figs. 2B, 4B1, Table 2).

In these microiontophoretic experiments, the amount of BIC or STY ejected in SC2-test was assessed qualitatively for each neuron by adjusting ejection currents to achieve a complete selective blockade of neuronal inhibition produced by pulsatile release of the agonist GABA or GLY, respectively (Fig. 3). Then, this ejection current was applied and maintained to eject the antagonist in a sustained manner throughout the next consecutive episode of AS in SC2-test. GABA and GLY inhibitions were terminated once selective blockade by BIC or STY, respectively, were confirmed. Indeed, for all cells examined with BIC $(n=12$, cats \#2, \#3) and STY ( $n=9$, cat \#3), GABA and GLY were ejected throughout the second $\mathrm{SC}$ in a pulsatile manner at regular intervals [mean GABA ejection current $( \pm \mathrm{SD}): 38.4 \pm 32.2 \mathrm{nA}, 10$ sec, $40 \mathrm{sec}$ intervals; GLY: $40.8 \pm 44.2 \mathrm{nA}, 10 \mathrm{sec}, 40 \mathrm{sec}$ intervals]. During the second SC, when BIC was ejected over an average time period of $14.9 \pm 5.9 \mathrm{~min}$ using an average ejection current of $34.3 \pm 25.8 \mathrm{nA}$, we measured a small (11.7\%), albeit statistically significant $(p<0.05)$, decrease in the AS-specific suppression of DSCT neuron spike rate compared with 38.1 and $33.0 \%$ AS-specific decrease in the first (control) and third (recovery) SCs, respectively (Table 2). For all cells tested with BIC, a plot of spike rate during W versus AS clearly indicated a shift toward the diagonal indicating reduced or no AS-specific inhibition in SC2-test when compared with SC1-control or SC3recovery (Fig. $5 B$ ).

Similar results were observed when the DSCT neurons tested with BIC were examined in each animal separately (cat $\# 2, n=9$ cells, cat \#3, $n=3$ cells). For example, group mean spike rate $( \pm \mathrm{SEM})$ for 9 cells tested with $\mathrm{BIC}(28.6 \mathrm{nA} \pm 14.0$, $13.7 \mathrm{~min} \pm 6.5)$ in cat \#2 decreased by $34.3 \%$ from $24.9 \pm 4.7$ during wakefulness to $16.2 \pm 2.8$ spikes/sec during AS in SC1-control ( $p<0.01$, ANOVA), by only $8.5 \%$ from $33.5 \pm 5.4$ to $29.6 \pm 5.4$ spikes $/ \mathrm{sec}$ in SC2-test $(p<0.05$, ANOVA), and by $33.0 \%$ from $28.0 \pm 3.3$ to $18.9 \pm 3.3$ spike/sec in SC3recovery ( $p<0.01$, ANOVA), respectively. In cat \#3, comparable reduction in AS-specific suppression by BIC (15.9 nA \pm $8.2,13.1 \mathrm{~min} \pm 2.4$ ) was observed for three cells. Here, we observed a $49.6 \%$ decrease from $18.8 \pm 2.2$ during $\mathrm{W}$ to $9.2 \pm$ 1.0 spikes/sec during AS in SC1-control ( $p<0.05$, ANOVA), a $12.0 \%$ decrease from $26.5 \pm 3.5$ to $23.4 \pm 3.9$ spikes $/ \mathrm{sec}$ in SC2-test ( $p>0.05$, ANOVA), and by $33.6 \%$ from $25.9 \pm 2.0$ to $17.0 \pm 0.10$ spikes/sec in SC3-recovery $(p<0.05)$, respectively. These data indicate that the $\mathrm{GABA}_{\mathrm{A}}$ antagonist $\mathrm{BIC}$ exerted very similar actions in blocking AS-specific suppression of DSCT neurons in each animal.

Propitious recording conditions in one animal (cat \#3) allowed us to test the action of the GLY antagonist STY in blocking AS-specific suppression on nine DSCT neurons. Here, STY released juxtacellularly during SC2-test $(59.8 \pm 34.0 \mathrm{nA} ; 14.1 \pm 8.3$ min) also abated the AS-specific suppression of spike rate when compared against SC1-control and SC3-recovery. For these cells 


\section{A. \\ Selective Blockade of \\ GABA Inhibition}

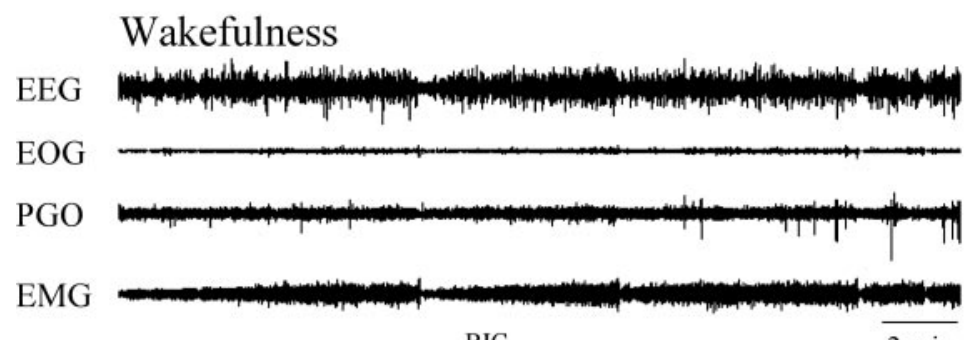

B.

\section{Selective Blockade of GLY Inhibition}

\section{Wakefulness}
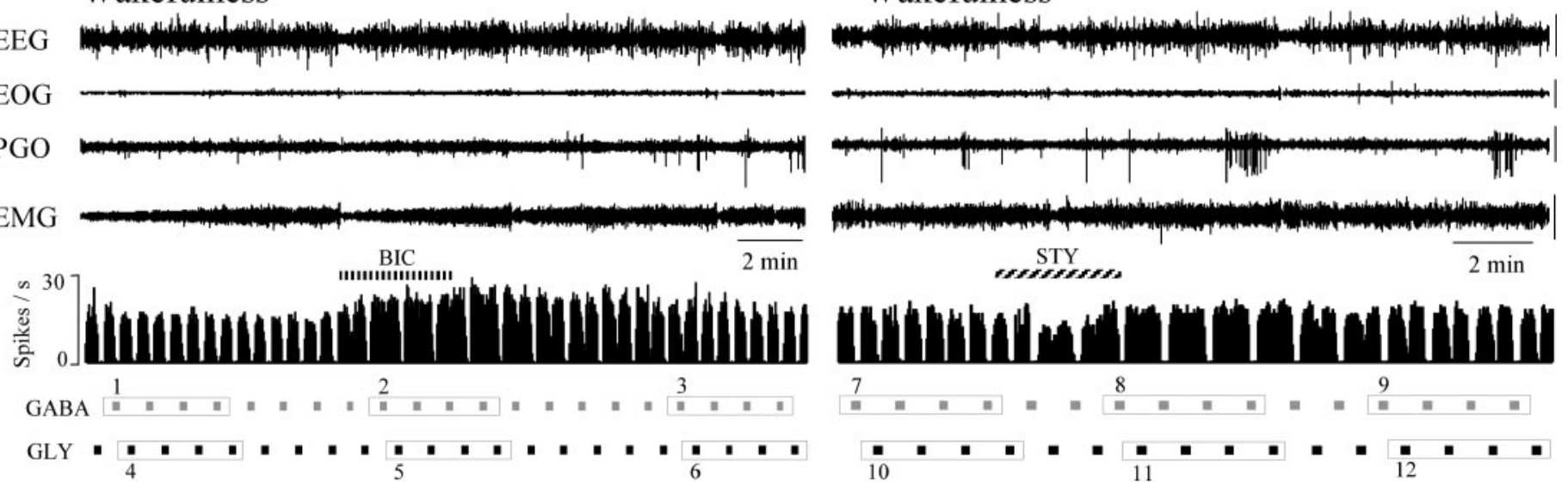
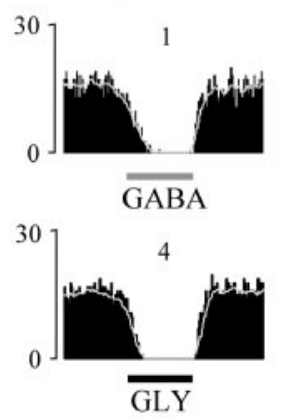

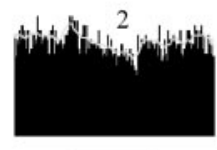

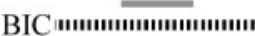

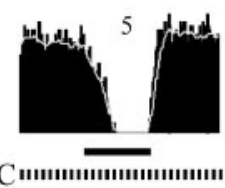

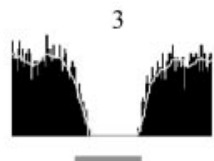

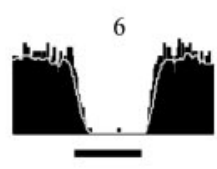

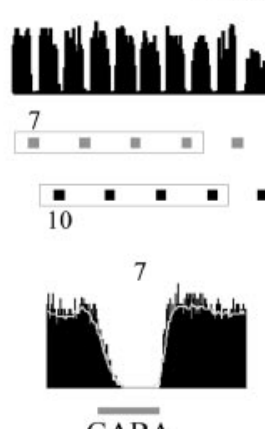

$\overline{\mathrm{GABA}}$

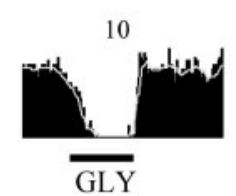

STY erevereverese

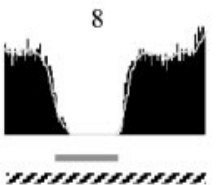

11

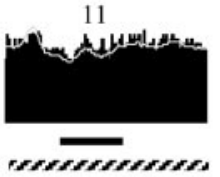

STY ereveresereses
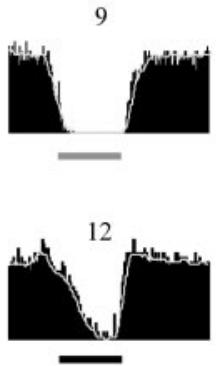

…

Figure 3. Selective blockade of GABA inhibition by BIC $(A)$ and GLY inhibition by STY $(B)$ of a DSCT neuron during quiet wakefulness. The first four traces represent the animal's behavioral state, as indicated by EEG, EOG, PGO, and EMG waveform activity. Calibration: $50 \mu \mathrm{V}$. The fifth trace in $A$ and $B$ represents the spike activity of the cell continuously plotted as a rate meter histogram during regular applications of GABA (80 nA) and GLY $(100 \mathrm{nA})(10 \mathrm{sec}$ ejection period, $40 \mathrm{sec}$ interval). Four consecutive responses to GABA and GLY around BIC $(A)$ and STY $(B)$ are highlighted by boxed enclosures. Corresponding computer-averaged peridrug histograms are plotted and numbered in the two bottom rows of labeled plots. BIC (66 nA, 230 sec) reversibly and selectively abolished inhibition by GABA ( $A$, compare average histogram plots 1-3 vs 4-6), whereas STY (90 nA, 180 sec) reversibly and selectively abolished inhibition by GLY ( $B$, compare average histogram plots 7-9 vs 10-12). Spontaneous spike activity of this DSCT neuron was enhanced by BIC and STY. The ejection currents used for BIC and STY to selectively block GABA and GLY, respectively, were then applied in a sustained fashion throughout SC2-test (see Paradigm 2, Fig. 2, Table 2).

tested with STY, the relative AS-specific decrease in spike rate in the second SC measured only $14.6 \%(p<0.05 ; n=9)$ compared with $37.2 \%$ and $26.1 \%$ in the first and third SCs, respectively (Fig. 4B3, Table 2).

Hence, a single inhibitory amino acid antagonist markedly reduced the AS-specific suppression of spike rate and only a small residual component remained. In six DSCT neurons, we continuously coapplied BIC (42.2 $\pm 26.0 \mathrm{nA})$ and STY $(71.9 \pm 29.8 \mathrm{nA})$ over $17.1 \pm 10.3 \mathrm{~min}$ and observed an abolition of the AS-related suppression of spike rate (Fig. 4B4, Table 2). Indeed, during the second SC, there was a tendency for the spike rate of these cells to be enhanced rather than inhibited during AS in the presence of both antagonists.

BIC $(n=12$; cats \#2, 3$)$, STY $(n=9$; cat \#3), or both agents together $(n=6$; cat \#3), also significantly enhanced DSCT neuronal firing rate during the state of wakefulness (Table 2) $(p<0.05)$. A noticeable effect by BIC and STY in two neurons was a shift from regular firing spike pattern to a burst-pause pattern after sustained coadministration of these agents (Fig. $4 B 4$ ). Frequency plots in Figure $5 B-D$ depicting the spike rate observed during wakefulness versus AS in each of the three SCs for individually recorded DSCT neurons indicate that BIC and/or
STY abolished or markedly reduced the difference in firing rate during AS versus wakefulness. This reduction in the difference of firing rate between AS and W was not simply the result of the increase in cell excitability exerted by these agents (e.g., frequency plots in Fig. $5 D$ vs $B, C$ ) but rather as a blockade of GABA and GLY receptors activated during AS. Indeed, for those cells where baseline firing rates during wakefulness before and during BIC or STY did not differ, the blockade of AS-specific suppression was still clearly evident.

\section{Excitatory amino acid-evoked activity}

Spontaneous spike activity of DSCT neurons could arise from a number of sources, including primary afferent, intrasegmental, and supraspinal sources, and could be mediated by a variety of neurotransmitters (Myslinski and Randic, 1977; Pioro et al., 1984; Maxwell et al., 1990; McGonigle et al., 1996; Jankowska et al., 1997). Anatomical and electropharmacological evidence exists that the neurotransmitter released specifically from group I muscle afferents to Clarke's column DSCT neurons is an excitatory amino acid, such as GLU (Maxwell et al., 1990; Walmsley and Nicol, 1991).

We also performed experiments in two animals whereby DSCT 
A.

EEG

EOG

PGO

EMG

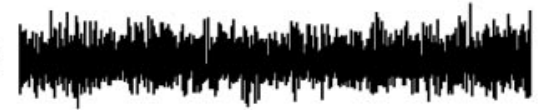

B.

Wakefulness

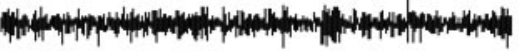

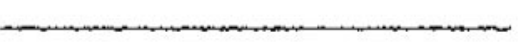

2y

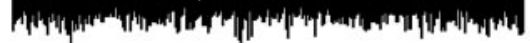

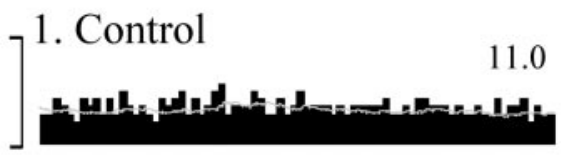

2. BIC

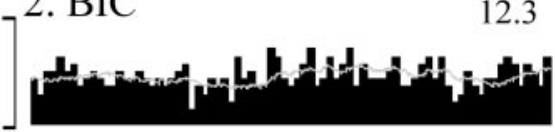

3. STY

10.4
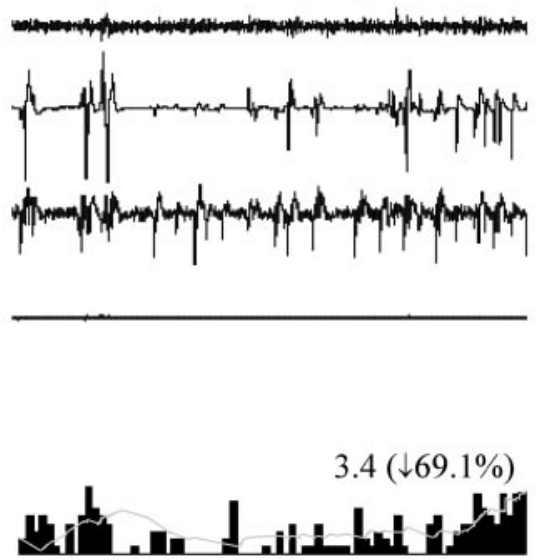

Active Sleep

Awakening

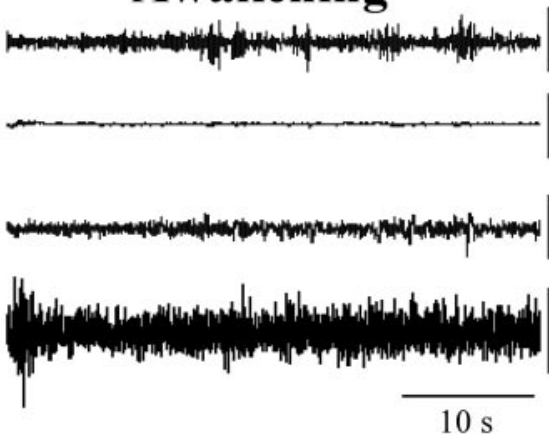

$10 \mathrm{~s}$

$7.1(\downarrow 35.5 \%)$

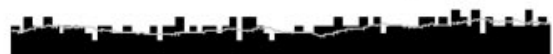

$14.5(\uparrow 17.9 \%)$

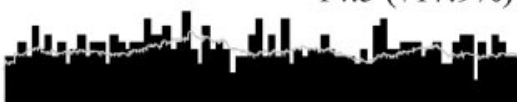

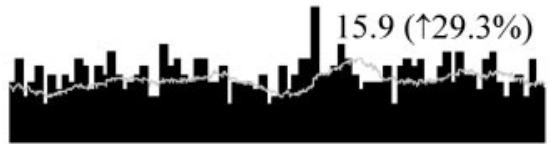

$9.6(\downarrow 7.7 \%)$
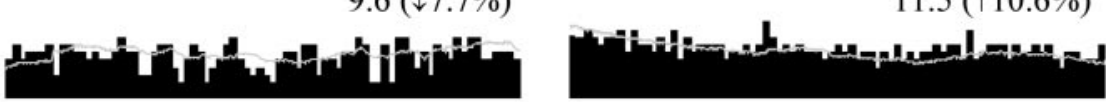

$14.6(\uparrow 9.8 \%)$

$13.5(\uparrow 1.5 \%)$
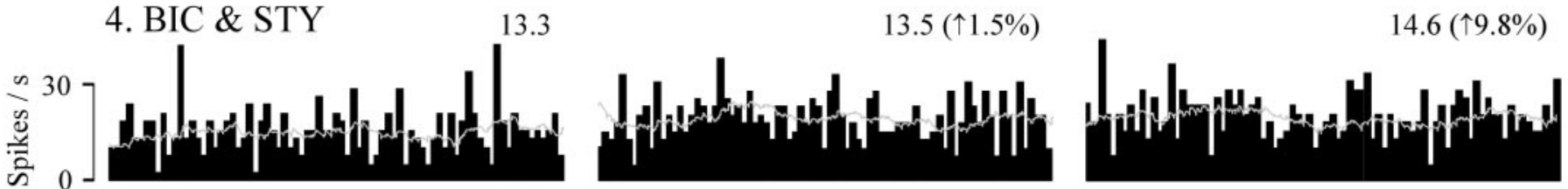

Figure 4. BIC and STY blockade of AS-specific suppression of spontaneous spike rate recorded from a DSCT neuron. $A$, The first four traces represent the animal's behavioral state, as indicated by EEG, EOG, PGO, and EMG activities. Calibration: $50 \mu$ V. B, Ratemeter histograms with superimposed sliding average (bin width, $10 \mathrm{sec}$ ) depicting the spike activity of the cell over $40 \mathrm{sec}$ plotted during wakefulness ( $W$ ), active sleep (AS), and awakening from AS (RW) under control and test (BIC, STY, BIC/STY) SCs. The numbers over the histograms represent mean firing rate. Spike rate decreased by $69.1 \%$ during $\mathrm{AS}$ in the control SC (B1), which was abolished by BIC ( $35 \mathrm{nA}, 12.5 \mathrm{~min})$ applied during the test SC (B2). In a subsequent test SC, STY microiontophoresis (40 nA, $10 \mathrm{~min}$ ) reduced AS-specific suppression by only 7.7\% (B3). Both antagonists (BIC $35 \mathrm{nA}$, STY $40 \mathrm{nA}, 17 \mathrm{~min}$ throughout a fifth test SC) blocked the AS-specific decrease and enhanced firing rate by $\sim 33 \%$ during wakefulness resulting in burst discharges $(B 4)$.
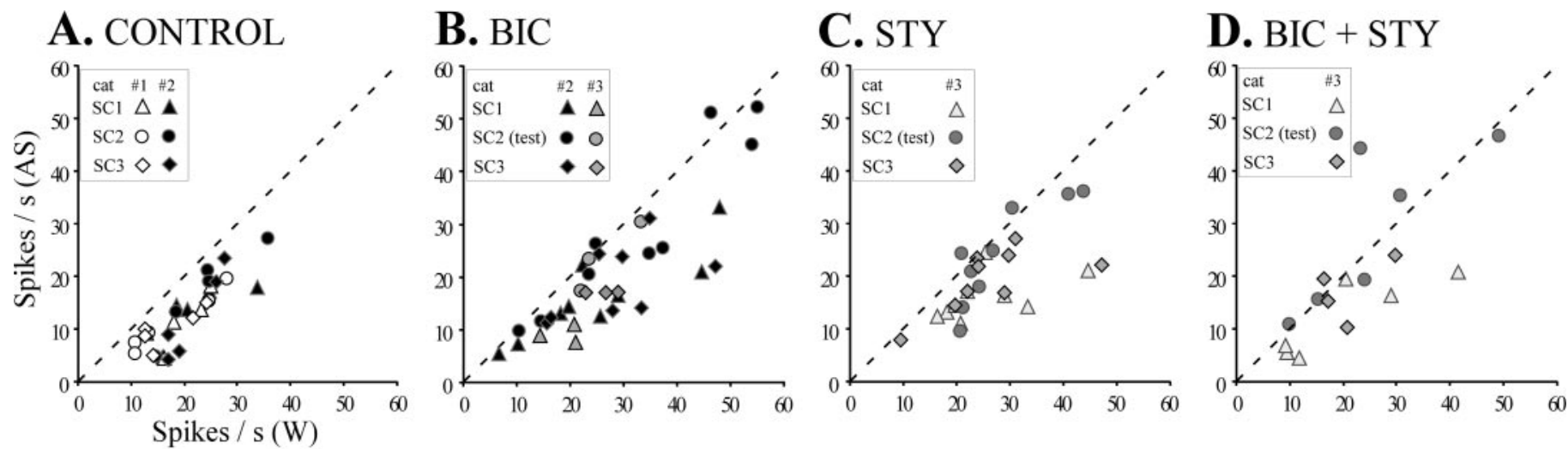

Figure 5. Plots $(A-D)$ depicting the firing rate during W versus AS for each cell in separate cats. Consistent AS-specific suppression occurred for each neuron in each animal across repeated control SCs (Paradigm 1, SC1, SC2, SC3, A) and contrasts with DSCT neurons examined using Paradigm 2 where most data points occur on or near the diagonal line indicating zero inhibition in SC2-test $(B-D)$. The symbols in the boxed enclosure for each plot represent data obtained for DSCT neurons across animals in paradigm $1(A)$ or paradigm $2(B-D)$. 
A.

Glutamate Excitation

Wakefulness

A.1 Control

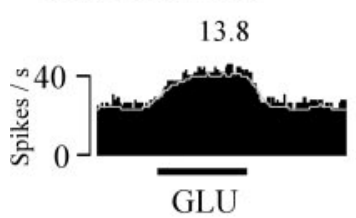

A.2 BIC
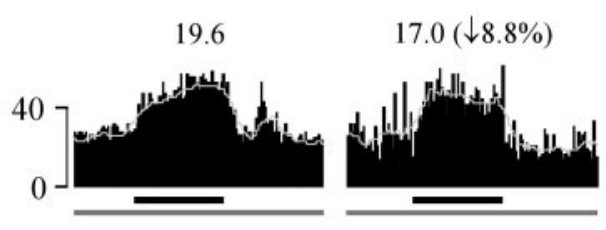

$\mathrm{BIC}$
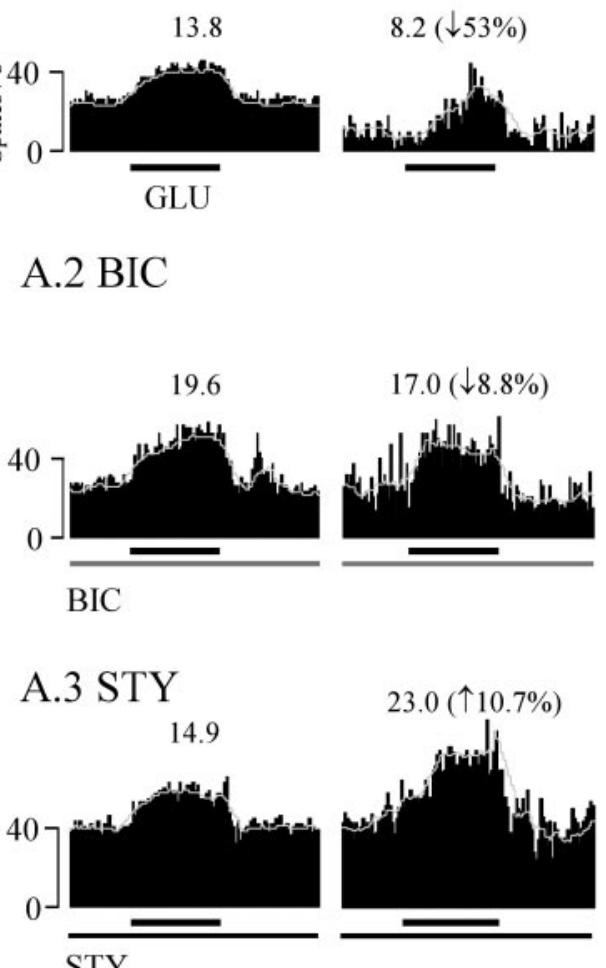

B.

Awakening
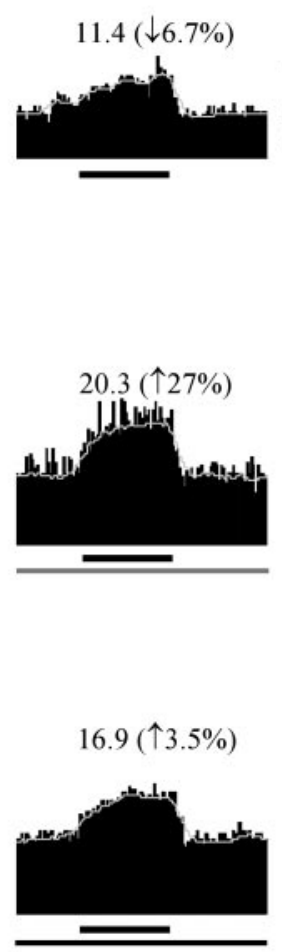

B.2 BIC
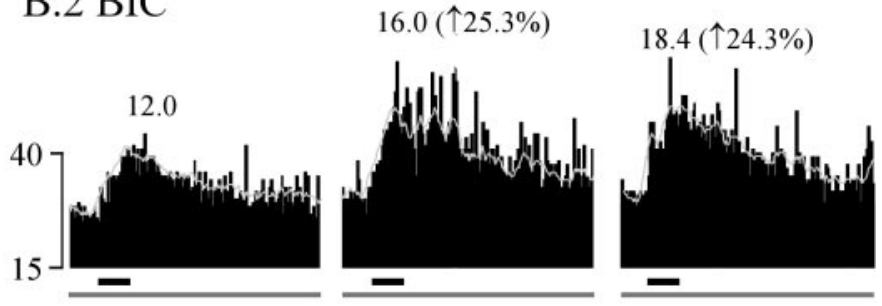

B.3 STY

AMPA Excitation
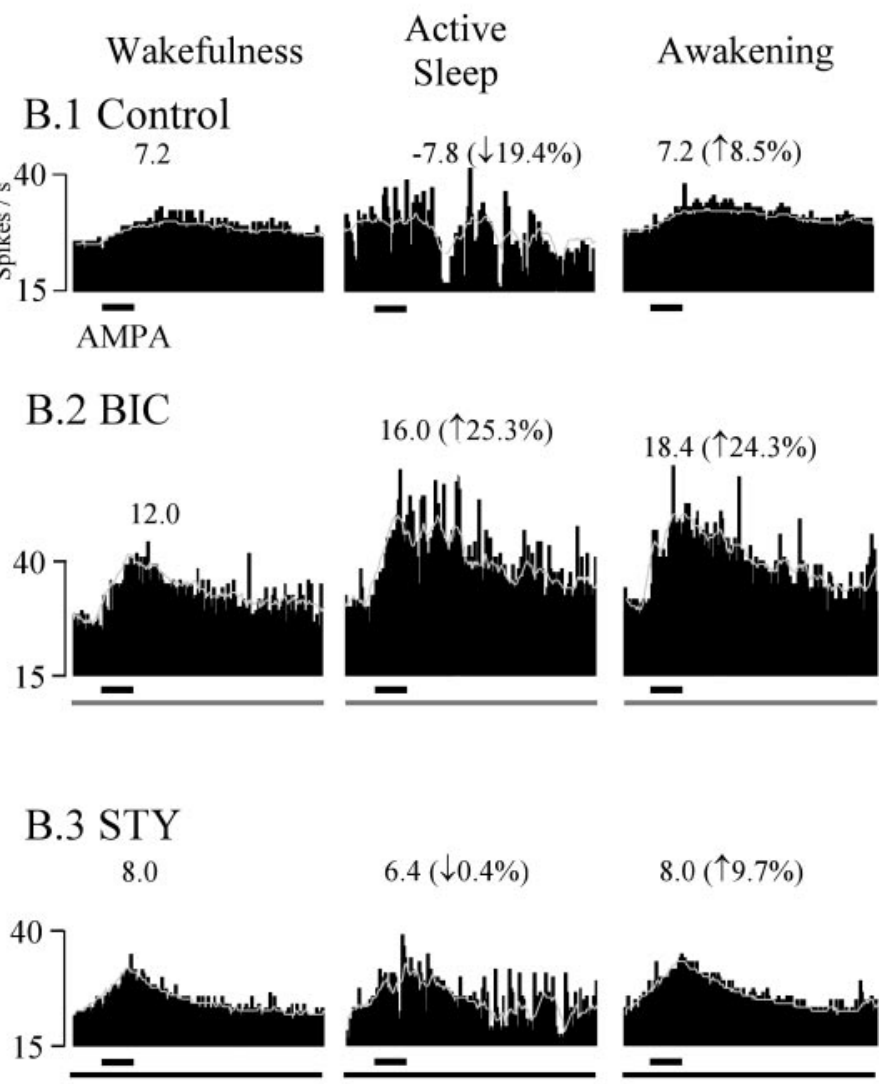

$6.4(\downarrow 0.4 \%)$

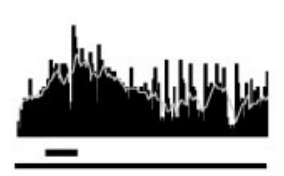

$8.0(\uparrow 9.7 \%)$

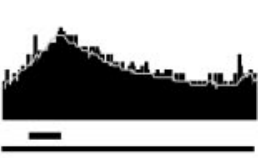

Figure 6. BIC and STY effects on AS-specific suppression of EAA-induced excitations of DSCT neurons. Each trace is a computer-averaged perievent histogram (with sliding average) of a DSCT neuron to consecutive GLU ( $A,-86 \mathrm{nA}, 10 \mathrm{sec}, 20 \mathrm{sec}$ intervals, 5 trials) or AMPA (B, $-60 \mathrm{nA}, 6 \mathrm{sec}, 60$ sec intervals, 4 trials) pulses applied during wakefulness, AS, and reawakening. Numbers over each perievent histogram represent the EAA-evoked response magnitude corrected for spontaneous spike activity (see Materials and Methods). Neurons were tested with BIC and STY in separate SCs. The control GLU response was suppressed by $53.0 \%$ during AS (A1, Control). During the sustained release of BIC (40 nA, 17 min; $A 2$, BIC), AS-specific suppression measured only $8.8 \%(A 2, B I C)$ and was abolished after STY administration ( $30 \mathrm{nA}, 21 \mathrm{~min} ; A 3, S T Y)$. In another DSCT neuron, the control AMPA-evoked response during wakefulness was reduced by $\sim 19 \%$ during AS (B1, Control). In contrast, in the presence of BIC, the AMPA-evoked response was facilitated by $\sim 25 \%$ during AS ( $25 \mathrm{nA}, 15.4 \mathrm{~min} ; B 2, B I C)$. In the presence of STY (50 nA, 19 min; B3, STY), AS-specific suppression was also abolished. Effects similar to $A$ and $B$ were obtained for five other DSCT neurons (GLU, $n=3$; AMPA, $n=2$ ). Spontaneous and EAA-evoked data from these seven DSCT neurons were combined and tabulated in Table 3.

neuronal excitation via glutaminergic neurotransmission from group I afferents was mimicked by controlled juxtacellular ejections of GLU and AMPA. Seven neurons were excited at regular intervals by juxtacellular microiontophoresis of the neural excitants GLU ( $n=4$; cat \# 2$)$ and AMPA $(n=3$; cat \#3). These excitatory agents were ejected in a pulsatile manner at regular intervals (GLU: $-90.7 \pm 32.2 \mathrm{nA}, 10 \mathrm{sec}, 20 \mathrm{sec}$ intervals; AMPA: $-70.7 \pm 11.0 \mathrm{nA}, 6 \mathrm{sec}, 60 \mathrm{sec}$ intervals). GLU- and AMPA-evoked responses were quantified (Soja et al., 2001b), and the degree of AS-related suppression was determined before, during, and after the release of BIC or STY. For each of these cells, inhibitory amino acid antagonists were ejected in SC2-test using currents that reversed inhibition of EAA-evoked responses caused by the sustained release of the respective agonist GABA or GLY (data not shown; however, see Soja et al., 2001b, their Fig. 2).

An example of AS-specific suppression of EAA-evoked responses before and during BIC or STY is illustrated in Figure 6. Computer-averaged GLU-evoked responses decreased by $53 \%$ during SC1-control (Fig. 6A1), only 8.8\% during sustained appli- cation of BIC during SC2-test (Fig. 6 $A 2$ ), and actually increased by $\sim 11 \%$ when STY was administered throughout another test SC (Fig. 6A3). BIC and STY exerted similar effects on three other DSCT neurons.

In three additional DSCT neurons, AMPA was tested using ejection currents that were adjusted to yield excitatory responses that originated from spontaneous baseline rates $(>15$ spikes/sec) yet were submaximal leaving room for possible disinhibition by BIC or STY. Consequently, during wakefulness, DSCT neuron excitatory responses to regular microiontophoretic administration of AMPA were consistent from trial to trial, yet relatively weak and prolonged. This contrasts with the more punctate excitatory response of DSCT neurons during GLU microiontophoresis in this preparation.

Nevertheless, AS-specific suppression of AMPA-evoked responses was observed. As illustrated in Figure $6 B$, computeraveraged AMPA-evoked responses decreased in one DSCT neuron by $19.4 \%$ in AS during SC1-control (Fig. 6B1, Control) and were markedly increased by $25.3 \%$ during AS when BIC was ejected continuously (25 nA, $15.4 \mathrm{~min}$ ) throughout SC2-test (Fig. 


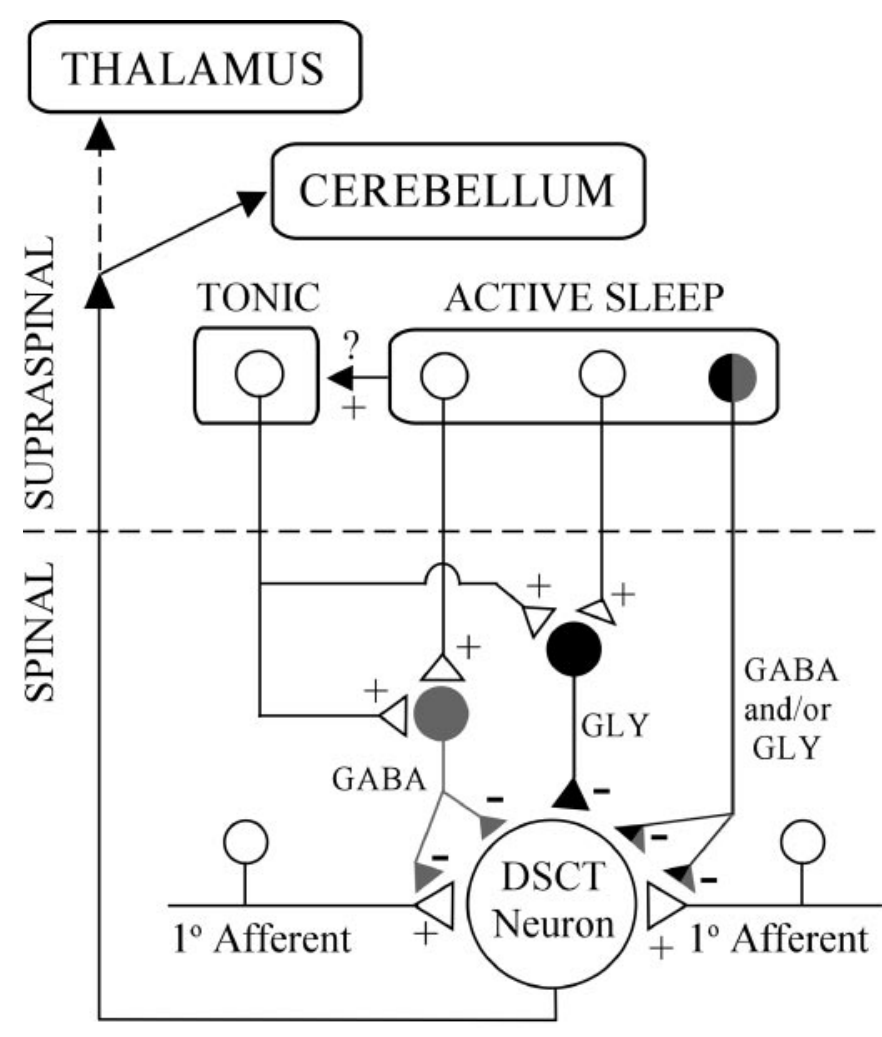

Figure 7. Hypothetical synaptic scenarios accounting for inhibition of transmission through DSCT during W and AS. Tonic control of DSCT neurons during W may be mediated by segmental GABA and GLY interneurons in the spinal cord via descending influences from bulbospinal pathways. During AS, reticulospinal influences may be engaged and impinge onto these or other interneurons to further enhance tonic inhibition. AS-specific supraspinal circuits may also increase the activity of tonic bulbospinal pathways. Aberrant GABA and GLY controls may result in "disinhibition" paraesthesias or dysesthesias (see Discussion).

$6 B 2, B I C$, Table 3). In a subsequent SC, AS-specific suppression was abolished by STY (50 nA, $19 \mathrm{~min}$ ) (Fig. 6B3, STY, Table 3). BIC and STY exerted similar effects on AMPA-evoked responses of two other DSCT neurons. Table 3 summarizes the group mean spontaneous and EAA-evoked spike rate of seven DSCT neurons in absolute and relative terms for the state of $\mathrm{W}, \mathrm{AS}$, and RW in control and test SCs. The AS-specific suppression of spontaneous and EAA-evoked responses measured 21.3 and $66.4 \%$, respectively and was abolished by BIC or STY (Table 3) $(p>0.05$, ANOVA).

These data, when taken together with the aforementioned studies (Maxwell et al., 1990; Walmsley and Nicol, 1991), suggest that the AS-specific suppression of short-latency synaptic responses of DSCT neurons, evoked by low-intensity peripheral nerve stimulation (Soja et al., 1995, 2001c), is likely to be sensitive to BIC and STY.

\section{DISCUSSION}

The present study used chronic recording and microiontophoretic methodologies to assess the pharmacological sensitivity of DSCT neurons to inhibitory amino acid agonists and their antagonists across the sleep-wake cycle. The responsiveness of DSCT neurons to GABA and GLY, the effect of BIC and STY on ASspecific inhibition, the possible neural pathways for AS-specific inhibition, and functional consequences of state-dependent aberrant GABA and GLY control of DSCT neurons will be discussed.

\section{Inhibition of DSCT neurons by GABA and glycine}

Few comparable data exist whereby the actions of juxtacellularly applied inhibitory and excitatory agents have been examined on DSCT neurons in chronic animals devoid of confounding neural distortion caused by anesthetics, paralytics, and recent surgery. Nevertheless, GABA and GLY readily suppressed, whereas GLU and AMPA excited DSCT neuronal spike activity during wakefulness and quiet sleep states, indicating that these neurons are endowed with receptors for "fast" inhibitory and excitatory neurotransmitters as shown for other sensory tract neurons (Curtis et al., 1986; Walmsley, 1991; Carlton et al., 1992; Dougherty et al., 1992; Westlund et al., 1992; Maxwell et al., 1995). The fact that BIC and STY, when administered during paradigm 2, reversibly and selectively blocked the well known inhibitory actions of locally applied GABA and GLY, respectively, further supports this notion (Curtis et al., 1968, 1971); while also providing an effective means of quantifying that adequate amounts of antagonists were released to alter AS-specific suppression of DSCT neurons.

\section{GABA and glycine involvement in AS-specific inhibition of ascending sensory transmission}

The results of the present study not only confirm previous observations that DSCT neurons are subjected to suppressor influences affecting both spontaneous (Soja et al., 1996) and EAA-induced postsynaptic excitations of DSCT neurons (Soja et al., 2001b) during the behavioral state of AS but, more importantly, establish the reliability of AS-specific suppression from individual neurons across multiple sleep cycles. The latter is essential for pharmacological studies on the AS-specific suppression of these neurons. Moreover, the present data provide a fundamental addition to our current knowledge base on the mechanisms underlying the regulation of afferent information through the DSCT across the sleep-wake cycle. In particular, the spontaneous, GLU- or AMPA-evoked activity of only those DSCT cells that are suppressed during AS (Soja et al., 2001b) are subjected to neural inhibition that is sensitive to the $\mathrm{GABA}_{\mathrm{A}}$ receptor antagonist BIC and the GLY receptor antagonist STY. If disfacilitation accounted principally for this state-dependent suppression, then BIC or STY would not be expected to block the decrease in spike rate that occurs consistently from one AS episode to another. On the contrary, the magnitude of AS-related suppression of DSCT neuron spontaneous or EAA-induced spike activity was found to be substantially reduced in the second SC by either of the antagonists or abolished when both agents were released concurrently. The fact that recovery of AS-specific suppression was observed for each cell in the third SC indicates that BIC and STY actions were attributable to a reversible, pharmacological blockade of localized GABAergic and glycinergic synaptic inhibition during this state. Although disfacilitation of DSCT neurons may occur, our data suggest it plays only a minor role if any in the reduced spike activity of these cells during AS.

Our data also suggest that only the fast inhibitory neurotransmitters GABA and GLY are released onto DSCT neurons during AS. Although recent evidence suggests $\mathrm{GABA}_{\mathrm{B}}$ receptormediated inhibition exists in the spinal cord (Curtis and Lacey, 1998), the present data indicate that the role of $\mathrm{GABA}_{\mathrm{B}}$ receptors in mediating the AS-specific suppression appears to be negligible.

GABA and GLY may be co-released from the same presynaptic terminals and act postsynaptically on the same target neuron, as inferred from evidence presented in other spinal cord studies (Chase et al., 1989; Rudomin et al., 1990; Jonas et al., 1998). 
Some of these terminals that corelease GABA and GLY may even form axo-axonic synapses with other afferent terminals (Maxwell and Riddell, 1999; Watson and Bazzaz, 2001). Our methodology and findings do not allow us to exclude these interesting possibilities but do indicate that the inhibition of DSCT neurons during AS is generated at synapses made with DSCT neurons at proximal and more distal dendritic sites (Chase et al., 1989; Soja et al., 1991; Pearson et al., 1995).

\section{Neural pathway of GABA- and GLY-mediated inhibition of DSCT neurons during AS}

The neural circuitry underlying GABA- and GLY-mediated inhibition of DSCT neurons during AS is not known. One possibility (Figs. 1, 7) may be that the blockade by BIC and STY of AS-related suppression reflects the state-dependent release of neurotransmitter from long descending GABAergic or glycinergic reticulospinal projections (Holstege and Bongers, 1991; Antal et al., 1996). Another possibility is that local segmental interneuron populations (Hongo et al., 1983; Jimenez et al., 1984; Solodkin et al., 1984; Rudomin et al., 1990; Kishikawa et al., 1995; Manjarrez et al., 2000; Takakusaki et al., 2001) could mediate GABAergic and glycinergic inhibition of DSCT neurons during AS. Presynaptic inhibition may operate in Clarke's column during AS via axo-axonic synapses (Maxwell and Riddell, 1999; Watson and Bazzaz, 2001), as well as GABA-mediated primary afferent depolarization, an index of presynaptic inhibition (Jankowska and Padel, 1984; Curtis et al., 1986; Walmsley et al., 1987). However, scant information exists in the literature regarding interneuron activity during AS (Kishikawa et al., 1995) and virtually nothing is known regarding the discharge patterns of identified last order inhibitory interneurons (Rudomin et al., 1990) during naturally occurring AS. Hence, future studies are needed to systematically investigate each of these possibilities.

GABA and GLY also postsynaptically inhibit spinal cord neurons via an increase in chloride conductance (Curtis et al., 1968; Barker and McBurney, 1979). GLY per se has also been identified as the neurotransmitter underlying the postsynaptic inhibition of lumbar motoneurons and the consequential atonia during naturally occurring AS (Chase et al., 1989; Soja et al., 1991). Hence, DSCT neurons are distinct from motoneurons in that both GABA and GLY appear to inhibit sensory tract neurons via presynaptic and/or postsynaptic processes (Figs. 1, 7). This, in turn, would dramatically attenuate sensory input to higher brain centers, including that which can be recruited by high-threshold muscle or flexor reflex afferents (Carli et al., 1967; Bosco and Poppele, 2001).

Given our current functional understanding of the DSCT (Mann, 1973; Walmsley, 1991; Bosco and Poppele, 2001), together with our findings reported here, the significance of the suppression of sensory information through this ascending pathway during AS becomes substantial especially when one considers possible pathological consequences. Perhaps, under normal circumstances, dampening of ascending prethalamic sensory transmission via Clarke's column DSCT and other neural pathways (Soja et al., 2001a), in concert with abolition of motor outflow, may be required to permit and/or maintain the integrity of AS (Chase and Morales, 1990; Soja et al., 1999). Our findings reported here indicate that GABA and GLY play a prominent role in this phenomenon and warrant further studies that are designed to identify the neural pathway underlying the inhibition of DSCT neurons during naturally occurring AS.
Functional consequences of inadequate GABA- and glycine-mediated inhibition of sensory transmission during wakefulness and active sleep

BIC and STY markedly enhanced the spontaneous as well as EAA-induced responses of DSCT neurons during wakefulness. The effects of BIC, for example, might be attributed to a blockade of small ion conductances that would enhance DSCT neuron excitability, leading to burst firing that is independent of a blockade of $\mathrm{GABA}_{\mathrm{A}}$ receptors (Debarbieux et al., 1998). Whereas BIC may exert actions on intrinsic properties of DSCT neurons, it is difficult to address this issue with BIC because it is not known if such intrinsic properties are present in these cells in vivo. Alternatively, a more plausible explanation for the increased firing rate during wakefulness may be the presence of tonic GABAergic and glycinergic inhibition that is unmasked by BIC and STY. This tonic inhibition may be part of those bulbospinal pathways controlling ascending sensory tract neurons (Holmqvist et al., 1960), and may likely contribute to mechanisms underlying abnormal clinical or preclinical repertoires of "disinhibition" allodynia (Yaksh, 1989; Sivilotti and Woolf, 1994; Sherman and Loomis, 1996; Khandwala and Loomis, 1998).

Commonly occurring sleep disorders with a possible link to abnormal GABA and GLY inhibition are restless legs syndrome (RLS) and the associated periodic limb movement disorder (PLM). RLS patients experience an imperative desire to move their lower legs because of paraesthesias or dysesthesias, which occurs at rest. These sensations inevitably worsen sleep architecture because associated PLMs persist throughout AS (Adler, 1997; Bucher et al., 1997; Hening, 1999; Glasauer, 2001).

The DSCT may indeed represent one possible ascending sensory pathway conveying abnormal sensory inputs to higher centers in RLS-PLM patients (Adler, 1997; Bucher et al., 1997; Hening, 1999). Patients with debilitating RLS-PLM are managed with dopaminergic drugs or gabapentin and benzodiazepines (Adler, 1997; Bucher et al., 1997; Hening, 1999; Glasauer, 2001). Taken together, the pathophysiology of RLS per se might arise from an intermittent loss of tonic GABAergic and glycinergic inhibitory controls (Wall, 1995; Lin et al., 1996; Sorkin et al., 1998) impinging on these and other ascending lumbar sensory neurons (Edgley and Jankowska, 1988; Huber et al., 1994; Schomburg et al., 2000; Soja et al., 2001b).

Under normal conditions, neural pathways projecting centripetally from as yet unidentified descending tracts (Figs. 1, 7) appear to engage during AS which, in turn, directly or indirectly inhibit DSCT neurons and/or upregulate tonic inhibitory controls emanating from higher brain centers (Fig. 7). Abnormal staterelated paresthesias associated with RLS, or increased sensations associated with sleep deprivation (Onen et al., 2000, 2001) may arise when behavioral state selective control systems involving GABA and GLY fail. Such scenarios might occur in isolation or in concert with other well defined mechanisms for neuronal plasticity in ascending sensory pathways (Woolf and Salter, 2000).

The results of the present study suggest that during quiet wakefulness, DSCT neurons are subjected to dynamic, GABAergic, and glycinergic inhibition. Tonic inhibitory controls during wakefulness are further enhanced during AS. These data provide a foundation for studies designed to investigate the last order interneurons as well as the extent and magnitude of presynaptic and postsynaptic processes involved in the state-dependent control of prethalamic ascending sensory information conveyed by Clarke's column and other lumbar sensory pathways (Edgley and Jankowska, 1988; Schomburg et al., 2000; Soja et al., 2001a). 


\section{REFERENCES}

Adler CH (1997) Treatment of restless legs syndrome with gabapentin. Clin Neuropharmacol 20:148-151.

Antal M, Petko M, Polgar E, Heizmann CW, Storm-Mathisen J (1996) Direct evidence of an extensive GABAergic innervation of the spinal dorsal horn by fibres descending from the rostral ventromedial medulla. Neuroscience 73:509-518.

Barker JL, McBurney RN (1979) GABA and glycine may share the same conductance channel on cultured mammalian neurones. Nature 277:234-236.

Bosco G, Poppele RE (2001) Proprioception from a spinocerebellar perspective. Physiol Rev 81:539-568.

Bucher SF, Seelos KC, Oertel WH, Reiser M, Trenkwalder C (1997) Cerebral generators involved in the pathogenesis of the restless legs syndrome. Ann Neurol 41:639-645.

Canadian Council on Animal Care (1993) Guide to the care and use of experimental animals, Ed 2. Ottawa: Bradda

Carli G, Diete-Spiff K, Pompeiano O (1967) Cerebellar responses evoked by somatic afferent volleys during sleep and waking. Arch Ital Biol 105:499-528.

Carlton SM, Westlund KN, Zhang D, Willis WD (1992) GABAimmunoreactive terminals synapse on primate spinothalamic tract cells. J Comp Neurol 322:528-537.

Chase MH, Morales FR (1990) The atonia and myoclonia of active (REM) sleep. Annu Rev Psychol 41:557-584.

Chase MH, Soja PJ, Morales FR (1989) Evidence that glycine mediates the postsynaptic potentials that inhibit lumbar motoneurons during the atonia of active sleep. J Neurosci 9:743-751.

Curtis DR, Lacey G (1998) Prolonged GABA(B) receptor-mediated synaptic inhibition in the cat spinal cord: an in vivo study. Exp Brain Res 121:319-333.

Curtis DR, Hosli L, Johnston GA, Johnston IH (1968) The hyperpolarization of spinal motoneurones by glycine and related amino acids. Exp Brain Res 5:235-258.

Curtis DR, Duggan AW, Felix D, Johnston GA (1971) Bicuculline, an antagonist of GABA and synaptic inhibition in the spinal cord of the cat. Brain Res 32:69-96.

Curtis DR, Gynther BD, Malik R (1986) A pharmacological study of group I muscle afferent terminals and synaptic excitation in the intermediate nucleus and Clarke's column of the cat spinal cord. Exp Brain Res 64:105-113.

Debarbieux F, Brunton J, Charpak S (1998) Effect of bicuculline on thalamic activity: a direct blockade of IAHP in reticularis neurons. J Neurophysiol 79:2911-2918.

Dougherty PM, Palecek J, Paleckova V, Sorkin LS, Willis WD (1992) The role of NMDA and non-NMDA excitatory amino acid receptors in the excitation of primate spinothalamic tract neurons by mechanical, chemical, thermal, and electrical stimuli. J Neurosci 12:3025-3041.

Edgley SA, Jankowska E (1988) Information processed by dorsal horn spinocerebellar tract neurones in the cat. J Physiol (Lond) 397:81-97.

Glasauer FE (2001) Restless legs syndrome. Spinal Cord 39:125-133.

Hening WA (1999) Restless legs syndrome. Curr Treat Options Neurol $1: 309-319$.

Holmqvist B, Lundberg A, Oscarsson O (1960) Supraspinal inhibitory control of transmission to three ascending spinal pathways influenced by flexion reflex afferents. Arch Ital Biol 98:60-80.

Holstege JC, Bongers CM (1991) A glycinergic projection from the ventromedial lower brainstem to spinal motoneurons. An ultrastructural double labeling study in rat. Brain Res 566:308-315.

Hongo T, Jankowska E, Ohno T, Sasaki S, Yamashita M, Yoshida K (1983) The same interneurones mediate inhibition of dorsal spinocerebellar tract cells and lumbar motoneurones in the cat. J Physiol (Lond) 342:161-180.

Huber J, Grottel K, Celichowski J (1994) Dual projections of the ventromedial lamina VI and the medial lamina V II neurones in the second sacral spinal cord segment to the thalamus and the cerebellum in the cat. Neurosci Res 21:51-57.

Jankowska E, Padel Y (1984) On the origin of presynaptic depolarization of group I muscle afferents in Clarke's column in the cat. Brain Res 295:195-201.

Jankowska E, Hammar I, Djouhri L, Heden C, Szabo Lackberg Z, Yin XK (1997) Modulation of responses of four types of feline ascending tract neurons by serotonin and noradrenaline. Eur J Neurosci 9:13751387.

Jimenez I, Rudomin P, Solodkin M, Vyklicky L (1984) Specific and nonspecific mechanisms involved in generation of PAD of group Ia afferents in cat spinal cord. J Neurophysiol 52:921-940.

Johansson H, Silfvenius H (1977) Axon-collateral activation by dorsal spinocerebellar tract fibres of group I relay cells of nucleus $\mathrm{Z}$ in the cat medulla oblongata. J Physiol (Lond) 265:341-369.

Jonas P, Bischofberger J, Sandkuhler J (1998) Corelease of two fast neurotransmitters at a central synapse. Science 281:419-424.

Khandwala H, Loomis CW (1998) Milacemide, a glycine pro-drug, in- hibits strychnine-allodynia without affecting normal nociception in the rat. Pain 77:87-95.

Kishikawa K, Uchida H, Yamamori Y, Collins JG (1995) Low-threshold neuronal activity of spinal dorsal horn neurons increases during REM sleep in cats: comparison with effects of anesthesia. J Neurophysiol 74:763-769.

Lavigne G, Zucconi M, Castronovo C, Manzini C, Marchettini P, Smirne S (2000) Sleep arousal response to experimental thermal stimulation during sleep in human subjects free of pain and sleep problems. Pain 84:283-290.

Lin Q, Peng YB, Willis WD (1996) Inhibition of primate spinothalamic tract neurons by spinal glycine and GABA is reduced during central sensitization. J Neurophysiol 76:1005-1014.

Manjarrez E, Rojas-Piloni JG, Jimenez I, Rudomin P (2000) Modulation of synaptic transmission from segmental afferents by spontaneous activity of dorsal horn spinal neurones in the cat. J Physiol (Lond) 529:445-460

Mann MD (1973) Clarke's column and the dorsal spinocerebellar tract: a review. Brain Behav Evol 7:34-83.

Maxwell DJ, Riddell JS (1999) Axoaxonic synapses on terminals of group II muscle spindle afferent axons in the spinal cord of the cat. Eur J Neurosci 11:2151-2159.

Maxwell DJ, Todd AJ, Kerr R (1995) Colocalization of glycine and GABA in synapses on spinomedullary neurons. Brain Res 690:127-132.

Maxwell DJ, Christie WM, Ottersen OP, Storm-Mathisen J (1990) Terminals of group Ia primary afferent fibres in Clarke's column are enriched with L-glutamate-like immunoreactivity. Brain Res 510 346-350.

McGonigle DJ, Maxwell DJ, Shehab SA, Kerr R (1996) Evidence for the presence of neurokinin-1 receptors on dorsal horn spinocerebellar tract cells in the rat. Brain Res 742:1-9.

Myslinski NR, Randic M (1977) Responses of identified spinal neurones to acetylcholine applied by micro-electrophoresis. J Physiol (Lond) 269:195-219.

National Research Council (1996) Guide for the care and use of laboratory animals. Washington, DC: National Academy.

Nielsen TA, McGregor DL, Zadra A, Ilnicki D, Ouellet L (1993) Pain in dreams. Sleep 16:490-498.

Onen SH, Alloui A, Eschalier A, Dubray C (2000) Vocalization thresholds related to noxious paw pressure are decreased by paradoxical sleep deprivation and increased after sleep recovery in rat. Neurosci Lett 291:25-28.

Onen SH, Alloui A, Gross A, Eschallier A, Dubray C (2001) The effects of total sleep deprivation, selective sleep interruption and sleep recovery on pain tolerance thresholds in healthy subjects. J Sleep Res $10: 35-42$.

Pearson JC, Alvarez FJ, Sedivic MJ, Torbeck L, Dewey DE, Fyffe REW (1995) Immunohistochemical analysis of the distribution of glycine receptors on dorsal spinocerebellar tract neurons in the cat. Soc Neurosci Abstr 21:980.

Pioro EP, Hughes JT, Cuello AC (1984) Demonstration of substance P immunoreactivity in the nucleus dorsalis of human spinal cord. Neurosci Lett 51:61-65.

Rudomin P, Jimenez I, Quevedo J, Solodkin M (1990) Pharmacologic analysis of inhibition produced by last-order intermediate nucleus interneurons mediating nonreciprocal inhibition of motoneurons in cat spinal cord. J Neurophysiol 63:147-160.

Schomburg ED, Jankowska E, Wiklund Fernstrom K (2000) Nociceptive input to ascending tract neurones forwarding information from low threshold cutaneous and muscle afferents in cats. Neurosci Res 38:117-120.

Sherman SE, Loomis CW (1996) Strychnine-sensitive modulation is selective for non-noxious somatosensory input in the spinal cord of the rat. Pain 66:321-330

Sivilotti L, Woolf CJ (1994) The contribution of GABAA and glycine receptors to central sensitization: disinhibition and touch-evoked allodynia in the spinal cord. J Neurophysiol 72:169-179.

Soja PJ, Lopez-Rodriguez F, Morales FR, Chase MH (1991) The postsynaptic inhibitory control of lumbar motoneurons during the atonia of active sleep: effect of strychnine on motoneuron properties. J Neurosci 11:2804-2811.

Soja PJ, Fragoso MC, Cairns BE, Oka JI (1995) Dorsal spinocerebellar tract neuronal activity in the intact chronic cat. J Neurosci Methods 60:227-239.

Soja PJ, Fragoso MC, Cairns BE, Jia WG (1996) Dorsal spinocerebellar tract neurons in the chronic intact cat during wakefulness and sleep: analysis of spontaneous spike activity. J Neurosci 16:1260-1272.

Soja PJ, Cairns BE, Kristensen MP (1999) Transmission through ascending lumbar sensory pathways: dependence on behavioral state. In: Handbook of behavioral state control: cellular and molecular mechanisms (Lydic R, Baghdoyan H, eds), pp 521-544. Boca Raton, FL: CRC

Soja PJ, Pang W, Taepavarapruk N, McErlane SA (2001a) Spontaneous spike activity of spinoreticular tract neurons during sleep and wakefulness. Sleep 24:18-25.

Soja PJ, Pang W, Taepavarapruk N, Cairns BE, McErlane SA (2001b) 
On the reduction of spontaneous and glutamate-driven spinocerebellar and spinoreticular tract neuronal activity during active sleep. Neuroscience 104:199-206.

Soja PJ, Fabian L, Pang W, Taepavarapruk N, McErlane SA (2001c) Peripheral nerve-evoked activity of dorsal spinocerebellar tract (DSCT) neurons decreases during active sleep. Soc Neurosci Abstr 27:1060.

Solodkin M, Jimenez I, Rudomin P (1984) Identification of common interneurons mediating pre- and postsynaptic inhibition in the cat spinal cord. Science 224:1453-1456.

Sorkin LS, Puig S, Jones DL (1998) Spinal bicuculline produces hypersensitivity of dorsal horn neurons: effects of excitatory amino acid antagonists. Pain 77:181-190.

Symons D (1993) The stuff that dreams aren't made of: why wake-state and dream-state sensory experiences differ. Cognition 47:181-217.

Takakusaki K, Kohyama J, Matsuyama K, Mori S (2001) Medullary reticulospinal tract mediating the generalized motor inhibition in cats: parallel inhibitory mechanisms acting on motoneurons and on interneuronal transmission in reflex pathways. Neuroscience 103:511-527.

Wall PD (1995) Do nerve impulses penetrate terminal arborizations? A pre-presynaptic control mechanism. Trends Neurosci 18:99-103.

Walmsley B (1991) Central synaptic transmission: studies at the connec- tion between primary afferent fibres and dorsal spinocerebellar tract (DSCT) neurones in Clarke's column of the spinal cord. Prog Neurobiol 36:391-423.

Walmsley B, Nicol MJ (1991) The effects of Ca2+, Mg2+ and kynurenate on primary afferent synaptic potentials evoked in cat spinal cord neurones in vivo. J Physiol 433:409-420.

Walmsley B, Wieniawa-Narkiewicz E, Nicol MJ (1987) Ultrastructural evidence related to presynaptic inhibition of primary muscle afferents in Clarke's column of the cat. J Neurosci 7:236-243.

Watson AH, Bazzaz AA (2001) GABA and glycine-like immunoreactivity at axoaxonic synapses on 1a muscle afferent terminals in the spinal cord of the rat. J Comp Neurol 433:335-348.

Westlund KN, Carlton SM, Zhang D, Willis WD (1992) Glutamateimmunoreactive terminals synapse on primate spinothalamic tract cells. J Comp Neurol 322:519-527.

Woolf CJ, Salter MW (2000) Neuronal plasticity: increasing the gain in pain. Science 288:1765-1769.

Yaksh TL (1989) Behavioral and autonomic correlates of the tactile evoked allodynia produced by spinal glycine inhibition: effects of modulatory receptor systems and excitatory amino acid antagonists. Pain $37: 111-123$ 